\title{
Análisis del marco jurídico regulatorio y del procedimiento de inversión en el sub sector eléctrico de las energías renovables en Nicaragua
}

\author{
Cinthya Lucia Jiménez Pichardo
}

Maestría en Derecho de Empresa con especialización en Asesoría Jurídica, Nicaragua cinthyajimenez89@gmail.com

\author{
Fecha de recibido: noviembre 2017 / Fecha de aprobación: junio 2018
}

\section{Resumen}

Nicaragua es un país que se caracteriza por tener recursos energéticos diversos y en abundancia, estos recursos naturales, gozan de un alto potencial para la explotación de energía renovable, ya sea hidroeléctrica, geotérmica, eólica, solar o biomasa. Por lo tanto, el análisis del marco jurídico regulatorio y del procedimiento de inversión referente a las energías renovables, se muestra como un estudio necesario ante las realidades económica, social y jurídica por las que en la actualidad atraviesa nuestro país. La ventajosa posición geográfica de Nicaragua, los abundantes recursos naturales que posee y la exuberante necesidad de inversión en este sector, hacen del presente estudio una interesante reflexión y aporte, al menos desde el punto de vista teórico jurídico. El desarrollo e incentivo por parte del Estado para la generación de energía a través de fuentes renovables, no solamente es idóneo sino necesario para el desarrollo del sub sector eléctrico nacional, siendo que proyectos de esta envergadura son el ideal colaborador para los proyectos de expansión energética y de electrificación rural que el Gobierno de Nicaragua ha impulsado hace varios años; con la publicación de la Ley No. 532, Ley para la promoción de generación eléctrica con fuentes renovables, se impulsó la generación limpia en el país, otorgando a los inversionistas una serie de beneficios fiscales, pero la misma no se muestra suficiente. El presente artículo muestra un análisis del marco jurídico regulatorio en el sub sector eléctrico de las energías renovables identificando oportunidades de mejora que coadyuvarían al desarrollo del sector.

\section{Palabras clave}

\author{
Energía renovable / Inversión / Incentivos
}

Nicaragua is a country characterized by diverse and abundant energy resources, which have a high potential for exploitation of renewable energy, whether hydro, geothermal, wind, solar or biomass energy. Therefore, the analysis of the regulatory and legal framework of the investment process, concerning renewable energy, shown as a necessary study to the economic, social and legal realities which are currently facing our country. The advantageous geographical position of Nicaragua, abundant natural resources owned, and lush need for investment in this sector make from this study an interesting reflection and contribution at least from a legal opinion. The development and encouragement by the state for energy generation from renewable sources is not only appropriate, but also necessary for the development of the sub national electricity sector being that projects the ideal partner for projects energy expansion and rural electrification that the Government of Nicaragua has been promoted by several years. With Law No. 532, Law for the promotion of energy generation from renewable sources, came a kind of clean generation in the country, giving to investors tax benefits, but it is not enough. This paper presents an analysis of the legal regulatory framework in the renewable energy sector identifying opportunities to improve the development of sector. 


\section{Key words}

Renewable energy / Investment / incentives

\section{Tabla de contenido}

I. Introducción. I. Sistema jurídico del sub sector eléctrico nacional.- I.I.Marco institucional del Sub Sector Eléctrico Nacional.- I.2. Marco jurídico regulatorio del Sub Sector Eléctrico Nacional.- I.2.I. Influencia de la normativa ambiental.- I.3. Plan Nacional de desarrollo humano.- I.4. Estado actual de las inversiones en el Sub Sector Eléctrico Nacional referente a energías renovables. 2. Sistema jurídico del Sub Sector Eléctrico en Guatemala.-I.2. Contexto Nacional de Guatemala. 2.2. Marco institucional y jurídico del Sub Sector Eléctrico en Guatemala. 3. Oportunidades de mejoras al sub sector eléctrico de energías renovables.- 4.I. Perspectivas y recomendaciones para avanzar en materia de energía renovables.- Conclusiones.Lista de referencias.-

\section{Introducción}

El Estado de Nicaragua, hace más de una década promulgó un importante compromiso frente a la generación eléctrica proveniente de energías renovables, compromiso que inicialmente quedó plasmado en el Decreto No. 13-2004 de Establecimiento de la Política Energética Nacional, publicado en La Gaceta, Diario Oficial No. 45 del 4 de marzo del 2004, en virtud del cual el Gobierno determina que el establecimiento de una política energética nacional, es el paso inicial y necesario para proceder al desarrollo de los planes estratégicos, en los cuales se establecerán los procedimientos y las acciones necesarias para el desarrollo del sector. El referido artículo también señala que es obligación del Estado, establecer los incentivos a las inversiones que produzcan costos aceptables, un suministro diversificado, una generación limpia y un uso eficiente.

Lo antes señalado ha sido confirmado por el Ministerio de Energía y Minas (MEM), a través de su portal web en el que han dado a conocer la composición del parque energético nacional, siendo el $52.43 \%$ de la matriz energética generado a través de la producción de energía limpia, de este porcentaje, el $20.71 \%$ corresponden a energía eólica; el $15.25 \%$ corresponde a energía geotérmica; un $9.66 \%$ a energía hidroeléctrica y $6.81 \%$ a biomasa.

En el ámbito nacional, diferentes organizaciones han propuesto la necesidad de una importante reforma al marco regulatorio del sector energético en materia de energía renovable, por ello surge la necesidad de la presente investigación, cuya finalidad es poder presentar un panorama de la situación jurídica actual en relación al sub sector eléctrico, específicamente en torno a energías renovables, plasmando sus generalidades y procurando describir la normativa y compararla con el de ordenamiento jurídico de Guatemala con el fin de encontrar elementos de mejora y luego puedan ser tomados en cuenta para el desarrollo del sector.

Durante el desarrollo del presente estudio realizamos algunas entrevistas a expertos del sector; así mismo con la intención de conocer la visión que desde el Ministerio de Energía y Minas se tiene como institución rectora del sector en torno al tema, solicitamos la comprobación de cierta información a la Dirección General de Electricidad y Recursos Renovables, sin embargo nuestra solicitud no fue aceptada, y a través de la Oficina de acceso a la información pública se 
nos indicó que solo se brindaría información a aquellos que ingresen solicitudes de licencias, es decir, a posibles inversionistas, por lo que se nos dificultó poder tener una apreciación del tema desde dicha entidad pública.

La presente investigación documental está diseñada bajo métodos de argumentación y sistematización de las fuentes documentales, las cuales serán el soporte para el análisis legislativo del sub sector eléctrico, esencialmente en materia de energías renovables. El análisis es deductivo, a través de la revisión de leyes, decretos, normativas técnicas, informes, etc., así como a través de una presentación de legislaciones de otro país que incentiven la atracción de inversión en el sector energético a través de fuentes renovables.

\section{Sistema jurídico del Sub Sector Eléctrico Nacional}

Sin embargo, reducir las emisiones nocivas, disminuir nuestra dependencia del petróleo extranjero, y el desarrollo de fuentes alternativas de energía renovable tiene beneficios que van más allá de la salud del medio ambiente, mejoran la salud personal, mejorar la seguridad nacional y fomentar la viabilidad económica de nuestra nación. Jim Clyburn. Político Estadounidense.

\section{I.I. Marco institucional del Sub Sector Eléctrico Nacional}

Desde 1920, Nicaragua forma parte de los procesos de industrialización eléctrica. Con el Gobierno del General José Santos Zelaya nace la primera de las muchas plantas eléctricas, denominada "Nicaragua Electric Plant", la segunda planta eléctrica se constituye alrededor del año de 1927 y se denominó "Central America Power Corporation" la cual según Informe nacional de monitoreo de la eficiencia energética de Nicaragua, de las Naciones Unidas (2015) contaba con una capacidad instalada de $2.2 \mathrm{MW}$.

Esta última, en el año de 194I fue adquirida por una entidad gubernamental y pasó a denominarse "Empresa de Luz y Fuerza de Managua" siendo parte del Ministerio de Fomento y Obras Públicas a finales del año de 1953.

Posteriormente, en los últimos meses del año de 1954 la Empresa de Luz y Fuerza de Managua, adquiere personería jurídica, patrimonio propio y plena capacidad para adquirir derechos y contraer obligaciones recibiendo el nombre de "Empresa Nacional de Luz y Fuerza" (ENALUF), a través del Decreto Legislativo No. 102, Ley Constitutiva de la Empresa Nacional de Luz y Fuerza Eléctrica, publicado en La Gaceta, Diario Oficial No. 239 del 23 de Octubre de 1954.

La referida normativa delegaba a ENALUF las funciones de generación, transmisión y distribución del suministro energético. Luego, en el año de 1979 a través de un Decreto Legislativo se constituyó el Instituto Nicaragüense de Energía (INE), adscrito al Gobierno Central, el cual asumió las mismas funciones de ENALUF, además de ente regulador.

Sin embargo, no es hasta 1985 mediante la creación de Ley Orgánica del Instituto Nicaragüense de Energía, constituida por Decreto el 6 de junio de 1985 y publicada en La Gaceta Diario Oficial No. 106, estableciendo en su artículo I que el INE es un ente descentralizado, con personalidad jurídica, duración indefinida, patrimonio propio y plena capacidad para adquirir derechos y contraer obligaciones, encargado de la regulación, supervisión y fiscalización del sector energía.

Posteriormente, a través del Decreto Administrativo No. 46-94, publicado en La Gaceta, Diario Oficial No. 204 del I de Noviembre de 1994 se creó la Empresa Nicaragüense de Electricidad (ENEL), pasando a asumir la generación, transmisión y distribución y comercialización de la electricidad (art. I), pero que en la actualidad fue transformada en un ente descentralizado del poder ejecutivo bajo la rectoría sectorial del Ministerio de Energía y Minas, a través del Decreto No. 46-94 publicado en La Gaceta Diario Oficial numerol72 del 10 de septiembre del 2012, 
cuya finalidad se suscribió a la generación de energía eléctrica mediante fuentes disponibles en especial la generada por recursos renovables.

Hasta esta época de la historia, el sector energético en Nicaragua se caracterizaba por contar con la presencia del Estado en todas sus actividades.

Luego, la década de los noventas marcó el inicio de la transformación institucional del sector energético nacional, las Naciones Unidas a través de la CEPAL han publicado (2015) que entre los años de 1980 y 2000 Nicaragua sufrió una evolución del marco institucional y normativo, propiciando mayor promoción en inversión, sobre todo a la capacidad instalada.

Esta evolución institucional, en gran medida fue gracias al inicio del proceso de privatización del sector eléctrico, y en este sentido con la aprobación de la Ley No. 272, Ley de la Industria Eléctrica, publicada en La Gaceta, Diario Oficial No. 74 del 23 de abril de 1998, y luego consolidada a través de la publicación en La Gaceta, Diario Oficial No. 172 del 10 de septiembre de 2012, en adelante Ley $272 / 1998$, se viene a regular la operatividad del mercado, estableciendo la obligación de Estado de asegurar el suministro de energía eléctrica al país, creando las condiciones propicias para que los agentes económicos puedan expandir la oferta de energía.

La misma normativa dispuso que la transmisión de la energía debería ser responsabilidad de la Empresa de Transmisión, como propietaria del Sistema Nacional de Transmisión (SNT), la cual debía de tener carácter estatal (art. 27). Posteriormente en el año 2007, se crea la Ley No. 583, Ley Creadora de la Empresa Nacional de Transmisión Eléctrica (ENATREL), publicada en La Gaceta, Diario Oficial No. 04 del 05 de Enero del 2007, en adelante Ley 583/2007.

En la referida década, Nicaragua se adhiere al Tratado marco que da origen al Sistema de Interconexión Eléctrica para América Central (SIEPAC), el cual fue aprobado legislativamente a través del Decreto 1804, Decreto de aprobación del Protocolo al tratado marco del mercado eléctrico de América Central, publicado en La Gaceta Diario Oficial número 15 de 23 de Enero de 1998.

En virtud de la evolución social, económica, y normativa por la que atravesaba el país respecto al sector energético, nació el Ministerio de Energía y Minas (MEM) a través de la Ley 6/2, Ley de Reforma y Adición a la Ley No. 290, Ley de Organización, Competencia y Procedimientos del Poder Ejecutivo, publicada en La Gaceta Diario Oficial No. 20 del 29 de Enero del 2007, convirtiéndose en el Órgano Rector del sector energético del país, según lo establecido en al art. 30 de la Ley No. 290 Ley de Organización, Competencia y Procedimientos del Poder Ejecutivo, publicada en La Gaceta Diario Oficial No. 35 del 22 de febrero del 20I3, así como por el art. 8 de la Ley 272/1998.

De esta manera, el sub sector eléctrico a nivel institucional está compuesto:

A nivel regional por: i) la Comisión Regional de Interconexión eléctrica (CRIE), que tiene como principal obligación la de regular las relaciones comerciales entre las instituciones públicas y privadas que se conectan al sistema, así como la responsabilidad de fijar las tarifas correspondientes; ii) el Ente Operador Regional (EOR), entre sus principales funciones se encuentra la de proponer a la CRIE los procedimientos de operación del Mercado y del uso de las redes de transmisión regional; Asegurar que la operación y el despacho regional de energía sea realizado con criterio económico, procurando alcanzar niveles adecuados de seguridad, calidad y confiabilidad.

A nivel Nacional: i) En la cúspide encontramos al Ministerio de Energía y Minas (MEM) como el órgano encargado de planificar las estrategias del desarrollo del sector energético nacional; ii) Paralelamente se encuentra el Instituto Nicaragüense de electricidad (INE) designado como el ente regulador y fiscalizador del sector energético; iii) Por debajo de estas instituciones 
encontramos el Centro Nacional de Despacho de Carga (CNDC), designado como responsable de la administración del Mercado Eléctrico Nacional y Regional, así como el responsable de la operación del Sistema Interconectado Nacional (SIN); iv) en última línea se encuentran los generadores, quienes son responsables de la generación eléctrica; la Empresa Nacional de Transmisión Eléctrica (ENATREL) responsable de la transmisión energética; las Distribuidoras, las cuales son responsable de la distribución de la energía; y por último los Consumidores.

La descripción institucional antes referida contiene las principales instituciones públicas que regulan el sub sector eléctrico del país, las cuales se diferencian específicamente por las funciones a las que atienden, $y$ por el sector al que se dirigen.

\section{I.2. Marco jurídico regulatorio del Sub Sector Eléctrico Nacional}

Como consecuencia de todas las transformaciones institucionales, por las que el país atravesó, en la actualidad, el sub sector eléctrico en Nicaragua se encuentra regulado por una serie de leyes, reglamentos, normativas y convenios internacionales, los cuales en el año $201 \mathrm{I}$ fueron reunidos en una compilación ordenada denominada "Digesto Jurídico del Sector Energético 201 I", a través del Decreto A. N. No. 6497, publicado en La Gaceta, Diario Oficial No. 2 I 2 del 9 de noviembre del $20 \mathrm{I}$ I, el cual dentro de sus considerandos justifica la necesidad de esta compilación al señalar:

Que en la actualidad, se estima que el ordenamiento jurídico nicaragüense contiene más de diez mil normas jurídicas, de las cuáles existe un alto porcentaje cuya vigencia no está claramente definida, lo que origina problemas en su aplicación, interpretación y ejecución, incidiendo negativamente en la confianza y certeza jurídica de la ciudadanía y extranjeros.

El principal objetivo del Digesto Jurídico del sector energético según dispone el art.l, es recopilar, ordenar, y consolidar las leyes del sector, con la finalidad de evitar contradicciones normativas y señalar aquellas normas jurídicas que ya no se encuentren vigentes, determinando de esta manera el marco jurídico regulatorio del sector energético nacional.

En este acápite enumeraremos y explicaremos las normativas que enmarcan el desarrollo del sub sector eléctrico, especialmente en materia de energía renovable, es decir, delimitaremos el marco legal para el desarrollo jurídico de proyectos energéticos a través de fuentes renovables.

La primera norma jurídica a la que haremos mención es la Constitución Política de la República de Nicaragua, publicada en La Gaceta, Diario Oficial No. 32 del día 18 de febrero del 2014, en su art. 102 determina que los recursos naturales son patrimonio nacional, y otorga autorización al Estado a celebrar contratos de explotación racional de los recursos naturales, siempre y cuando sea en interés de los nicaragüenses; de forma complementaria, el art. 100 regula la obligación del Estado de garantizar las inversiones nacionales o extranjeras, ya sea a mediano o largo plazo y que sean necesarias para el mejoramiento y desarrollo de la industria energética.

Sin duda alguna, el desarrollo del sector energético para un país como Nicaragua es trascendental, por lo que es necesario su encasillamiento a nivel constitucional. De esta regulación se derivan el resto de normas jurídicas que regulan el sector, las cuales deben de enmarcarse en los parámetros dispuestos por la Constitución Política de la República.

Continuamos nuestro análisis con la Ley No. 612, Ley de Reforma y Adición a la Ley No. 290, Ley de Organización, Competencia y Procedimientos del poder ejecutivo, publicada en La Gaceta Diario Oficial No. 20 del 29 de enero del 2007, su importancia radica en que instituye al Ministerio de Energía y Minas (MEM), como el órgano rector del sector energético del país así como la designación de sus funciones. Es así que el art. 30 de la ley establece que le corresponde al MEM formular, proponer, coordinar y ejecutar el plan estratégico y políticas públicas del 
sector, así como elaborar las normas, reglamentos y regulaciones técnicas que regirán las actividades de exploración, explotación, aprovechamiento, producción, transporte, transformación, distribución, manejo y uso de los recursos energéticos, y principalmente impulsar las políticas y estrategias que permitan el uso de fuentes alternas de energía para la generación de electricidad, entre otras funciones.

Pilar fundamental del marco regulatorio del sector energético es la Ley No. 272, Ley de la Industria Eléctrica, publicada en La Gaceta, Diario Oficial No. 172 del 10 de septiembre de 2012; podríamos considerarla como la norma jurídica trascendental para el sector, ya que en ésta se enuncian una serie de definiciones, y procedimientos necesarios para el desarrollo del mismo, además establece "el régimen legal para la industria eléctrica en todas sus etapas: generación, transmisión, distribución, comercialización, importación y exportación de energía" (BCIE, 20I0, p. 26).

El art. 18 de la citada norma confirma al Instituto Nicaragüense de Energía (INE) como el ente regulador, encargado de la supervisión y fiscalización de las actividades de la industria eléctrica; además establece en su art. 22 que la generación de energía eléctrica puede producirse mediante el aprovechamiento y transformación de cualquier fuente energética.

Es preciso tomar en cuenta, que la generación de energía a través de fuentes renovables implicaría al país, mayor energía a un menor costo, aumento de las exportaciones de energía y reducción al mínimo posible de las importaciones, además de colaborar con el cambio climático.

En este sentido, vale la pena replicar que Nicaragua posee un alto potencial para la generación de energía a través de fuentes renovables. Según Informe (20II) del Observatorio de Energías Renovables en América Latina y el Caribe, el país cuenta con un potencial de energía renovable identificado de aproximadamente unos 4,500 MW, "y solo se aprovecha alrededor del 5\% para la generación de energía eléctrica (p.12)".

Lo que antes hemos señalado "mayor energía a un menor costo" podría generar controversias, ya que uno de los argumentos que van en contra del desarrollo de las energías renovables se refiere a que el costo de generación de éstas puede variar dependiendo del precio del petróleo, incluso ser más costosa frente a la generación basada en combustibles fósiles.

Calero (2015) publicó:

En la VII Cumbre de las Américas que se realizó en Panamá del 9 al II de abril, el Presidente de la República Daniel Ortega Saavedra dijo que se ha tenido que frenar la ola de inversionistas interesados en invertir en energía renovable, haciendo hincapié que en este tiempo es más barato obtener energía a base de full oil ahora que bajó el precio del petróleo que generar energía a base de renovable.

La misma publicación señala:

Para el especialista peruano en temas energéticos, Luis Fernando Ochoa, el Gobierno es clave porque debe establecer metas que no sean a corto plazo, porque si bien es cierto que la energía térmica en este momento es más barata su generación que la renovable, no hay seguridad porque su precio es volátil y es un recurso no renovable y además contaminante...dijo que el problema de Nicaragua es que si se deja de invertir en renovables en cinco años quien asumirá las consecuencias no será el Gobierno sino los usuarios. 
Dolezal, A.; Majano, A.; Ochs, A.; Palencia, R. (20I3. p.4I) señalan que:

Hacer el cambio a la energía renovable puede tener ventajas significativas de costos sobre los combustibles fósiles. En general, las comparaciones de costos entre diversos tipos de generación de energía pueden ser difíciles debido a que diferentes factores influyen en el precio detallado de la electricidad, incluyendo los costos de producción, transmisión y distribución, subsidios, impuestos y regulaciones. Sin embargo....un estudio reciente de LCOE de Centroamérica realizado por el Banco Mundial comparó las tecnologías de energía geotérmica, energía hidroeléctrica y el combustible fósil y concluyó que las fuentes de energía renovable son más competitivas en cuanto a costos que las fuentes de energía basadas en combustible fósil.

La utilidad de las energías renovables va más allá de su costo de generación, estas contribuyen a la seguridad energética, ya que son fuentes autóctonas y reducen el riesgo de falta de suministro a largo plazo, además mejoran el desarrollo económico y comercial del país; desde el punto de vista medioambiental y social, las renovables, aunque también tienen algún impacto ambiental, emiten muchos menos contaminantes, lo que se traduce en menores daños sobre la salud y el entorno, es decir, se encuentra en armonía con el ambiente, y preparan al país para cuando el recurso fósil se agote. En síntesis, las energías renovables son más eficientes y económicas a largo plazo.

Continuando con el análisis de la Ley 272/1998, ésta regula el otorgamiento de licencias para la generación de energía, o concesiones, facultando al MEM para fijar y determinar los requisitos y procedimientos a los que estarán sujetas las solicitudes de licencias realizadas por los agentes económicos y/o inversionistas, en el mismo sentido, el art. 73 establece que el Estado a través del Ministerio de Energía y Minas, se reserva el derecho a rechazar todas o cualquiera de las solicitudes u ofertas recibidas, para suscribir un contrato de concesión o licencia.

Para llevar a cabo lo antes señalado, el MEM cuenta con una Dirección General de Electricidad y Recursos Renovables, que se encarga de gestionar y autorizar la obtención de licencias de generación, la cual dependerá de la fuente energética a utilizar o bien las correspondientes concesiones para la distribución de energía. El artículo 69 de la referida ley, establece que las licencias para generar electricidad serán otorgadas de acuerdo al tipo de inversión y a las fuentes de energía utilizadas en el caso de generación basada en recursos naturales, el Ministerio de Energía y Minas exigirá al interesado cumplir con los requisitos que exigen las leyes competentes. Vale la pena expresar, que a pesar que la normativa jurídica enuncia en su art. 69 al referirse a los requisitos para la obtención de licencias de generación "el Ministerio de Energía y Minas exigirá al interesado haber cumplido con los requisitos que exigen las leyes competentes" la ley como tal, no establece a detalle cuales serán estos requisitos, todo lo contrario, deja al arbitrio del MEM la estipulación de éstos, dotándolo de facultades discrecionales, y autorizándolo para rechazar solicitudes, sin determinar cuáles serán esas causales de rechazo, sin embargo, exige al interesado, requisitos que no se encuentran delimitados en el cuerpo normativo señalado, ni en el reglamento.

Lo anterior podríamos considerarlo como una vulneración al principio de legalidad tomando en consideración que éste debe ser el límite de actuación de las entidades gubernamentales y sus funcionarios, en este caso el MEM, debe de someter sus actuaciones a este principio, y no a la aplicación de normativas específicas de menor rango.

Estos requisitos que se muestran ausentes en la ley, han sido elaborados y delimitados a discrecionalidad del MEM y colgados en el portal web de la institución (www.mem.gob.ni), sin embargo, la problemática que se presenta no radica en la estipulación o no de los mencionados requisitos, sino la lesión al principio de legalidad, lo que podría derivar en inseguridad jurídica. 
Sucede lo contrario con la Ley No. 286. Ley Especial de Exploración y Explotación de Hidrocarburos, publicada en La Gaceta, Diario Oficial No. 109, del 12 Junio 1998, esta norma jurídica establece a partir del art. I I cuales deben ser los requisitos legales, técnicos y financieros que la empresa nacional o extranjera debe de cumplir si pretende suscribir contrato de exploración o explotación de hidrocarburos.

Un aspecto que no podemos dejar de mencionar son los denominados "incentivos fiscales" que la ley contempla en sus artículos 130 y $13 \mathrm{I}$, los cuales establecen exoneraciones por el periodo de tres años a los gravámenes, la importación de maquinaria, equipos, materiales e insumos destinados exclusivamente a la generación, transmisión, distribución y comercialización de la oferta y suministro de energía eléctrica para uso público, además de la exoneración de forma indefinida que se contempla para cualquier gravamen sobre los combustibles usados para generar electricidad, ya que pueden considerarse atractivos para la inversión en el sector.

Ahora bien, entrando en materia, el marco regulatorio de las energías renovables se encuentra regulado además de las leyes antes mencionadas, por la Ley No. 532, Ley para la promoción de generación eléctrica con fuentes renovables, publicada en La Gaceta, Diario Oficial No. 175 del 13 de septiembre del 2012, con sus reformas integradas en virtud de Digesto jurídico, y su más reciente reforma Ley No. 901, Ley de Reforma a la Ley No. 532, Ley para la Promoción de Generación Eléctrica con Fuentes Renovables, publicada en La Gaceta No. 106 del 09 de junio del 2015, en lo sucesivo Ley 532/2005, además de una serie de normas complementarias específicas por recursos, tales como: i) Ley No. 467, Ley de promoción sub-sector hidroeléctrico, publicada en La Gaceta, Diario Oficial No 174 del 12 de septiembre del año 2012, consolidada en Digesto Jurídico 201 I; ii) Ley 443, Ley de Exploración y Explotación de Recursos Geotérmicos, consolidada según Digesto Jurídico 20II, publicada en La Gaceta, Diario Oficial No 218, del 17 de Noviembre del 2014.

Hasta este punto hemos podido notar que existen leyes que regulan de forma general todo el sector, y leyes específicas como son las leyes que regulan el sub sector hidroeléctrico y geotérmico.

Dicho lo anterior, continuaremos nuestro análisis con la Ley No. 532/2005, Ley para la Promoción de Generación Eléctrica con Fuentes Renovables, la cual está dirigida a personas naturales, jurídicas o mixtas, y considerada de interés nacional (art. 5); cuyo objeto es promover el desarrollo de proyectos de generación eléctrica a través de fuentes renovables, producidos en forma sostenible, estableciendo incentivos fiscales, y derechos prioritarios en torno a la contratación de energía de fuentes renovables.

Esta ley, estipula que será el MEM, el encargado de estimular y promover las inversiones y desarrollo de proyectos de generación de electricidad con fuentes renovables promoviendo de forma prioritaria la inserción de energía renovable en la generación eléctrica del país.

El art. 3 de la Ley 532/2005, regula que los nuevos proyectos de generación de energía con fuentes renovables y las ampliaciones de los proyectos en operación con fuentes renovables deberán estar acordes con: i) La Política Energética Nacional; ii) Los lineamientos del Plan de Expansión Indicativo vigente; iii) Contribuir a diversificar la oferta de energía dentro de la matriz energética nacional; iv) Contribuir al adecuado abastecimiento del crecimiento energético del país; v) Contribuir al suministro necesario para el aumento de la cobertura eléctrica nacional y vi) Cumplir con los requisitos de la legislación ambiental del país.

Los aportes de esta normativa son muchos, entre ellos, el establecimiento de definiciones que complementan las enunciadas por la Ley de Industria eléctrica, así mismo, establece incentivos fiscales que coadyuven al desarrollo de proyectos de generación energética a través de fuentes renovables, siendo los siguientes: i) Exoneración del pago de los Derechos Arancelarios de 
Importación (DAl) de maquinaria, equipos, materiales e insumos destinados exclusivamente para las labores de pre-inversión y las labores de la construcción de las obras; ii) Exoneración del pago del Impuesto al Valor Agregado (IVA), sobre la maquinaria, equipos, materiales e insumos destinados exclusivamente para las labores de pre-inversión y la construcción de las obras; iii) Exoneración de todos los Impuestos Municipales vigentes sobre bienes inmuebles, ventas, matrículas durante la construcción del proyecto, por un período de 10 años a partir de la entrada en operación comercial del proyecto, la que se aplicará de la forma siguiente: exoneración del $75 \%$ en los tres primeros años; del $50 \%$ en los siguientes cinco años y el $25 \%$ en los dos últimos años; iv) Las inversiones fijas en maquinaria, equipos y presas hidroeléctricas estarán exentas de todo tipo de impuestos, gravámenes, tasas municipales, por un período de 10 años a partir de su entrada en operación comercial, y se exonera la construcción u operación de un proyecto bajo permiso de administración de agua por un máximo de diez años; v) Exoneración de todos los impuestos que pudieran existir por explotación de riquezas naturales por un período máximo de 5 años después del inicio de operación; vi) Exoneración del Impuesto de Timbres Fiscales (ITF) que pueda causar la construcción u operación del proyecto o ampliación por un período de 10 años.

La ley establece que los incentivos y beneficios fiscales antes descritos serán administrados por el Ministerio de Hacienda y Crédito Público (MHCP), estipulando que la referida institución pública deberá crear una normativa que contenga los requisitos y procedimientos para su utilización, previa aprobación del Ministerio de Energía y Minas.

En relación a lo anterior, debemos traer a colación el Acuerdo Ministerial No. 063-DGRER-0I22013, Especificaciones y criterios para el uso de los incentivos fiscales establecidos en la Ley No. 532, "Ley para la Promoción de Generación Eléctrica con Fuentes Renovables" y el establecimiento de la fecha de inicio de operación comercial, publicado en La Gaceta, Diario Oficial No. 163 del 29 de Agosto de 2013, el cual en su segundo acápite regula:

Los nuevos proyectos o las ampliaciones cuya potencia instalada sea menor o igual a 999 $\mathrm{kW}$, que clasifiquen como PGEFR por el MEM, para gozar de los beneficios fiscales establecidos en la Ley No. 532, "Ley para la promoción de generación eléctrica con fuentes renovables", deberán cumplir con los requisitos y procedimientos establecidos en los siguientes acuerdos interministeriales suscritos entre el Ministerio de Hacienda y Crédito Público y el Ministerio de Energía y Minas: i) Acuerdo Interministerial No. 042007 publicado en La Gaceta, Diario Oficial No. 27 del 7 de febrero de 2008; ii) Acuerdo Interministerial No. 0I-2008 publicado en La Gaceta, Diario Oficial No. 49 del 10 de marzo de 2008; y, iii) Acuerdo Interministerial MHCP-MEM No. 02-2010 publicado en La Gaceta, Diario Oficial No. 235 del 9 de diciembre de 2010.

Por otro lado, la Ley No. 532/2005 establece una obligación institucional de priorización de las energías renovables en las contrataciones por las distribuidoras, mandando a incluir dentro de los procedimientos de licitación, la contratación de energía proveniente de centrales eléctricas con energía renovable, prioritariamente hidroeléctricos, geotérmicos, eólicos, biomasa, delimitado como plazo mínimo 10 años.

La Ley también formula que los proyectos eólicos de generación de energía con el fin de ser habilitados para conectarse al Sistema Interconectado Nacional (SIN) deberán de coordinarse con la Centro Nacional de Despacho de Carga (CNDC) para demostrar que dicha generación no causa disturbios a la operación del SIN.

De forma general, la Ley 532/2005 cumple con su objeto, diseña una estructura que promueve la inversión en proyectos de generación eléctrica a través de fuentes renovables, que anudado con las características naturales del país, ha llamado la atención de inversionistas en el sector. La Asociación de Renovables de Nicaragua, en su plan estratégico 20I I-20I5, al referirse a esta ley expresa: "A pesar de que hace falta adecuar el marco regulatorio, se considera que se ha abierto 
las puertas para el aprovechamiento de las oportunidades de invertir en energías renovables, potenciando su crecimiento y desarrollo (p. 03)".

$Y$ es que la ley se centra exclusivamente en el otorgamiento de incentivos fiscales, careciendo de otros componentes necesarios como la delimitación de capacidad instalada de los proyectos, garantías administrativas $\mathrm{u}$ operacionales, $\mathrm{o}$ condiciones de contratación frente a las distribuidoras, a su vez delimita de forma muy general las fuentes energéticas que se consideraran renovables, y carece de un reglamento que determine los procedimientos de los procesos o solicitudes contemplados en la norma.

En síntesis, es una norma jurídica que podríamos denominar insuficiente, tomando en cuenta al sector que está dirigida y la importancia económica, jurídica y social que representa, siendo que proyectos de este tipo generan diversidad de beneficios, tales como empleos para muchos pobladores, desarrollo tecnológico y disminución del calentamiento global.

Por lo que se refiere a la Ley No. 467, Ley de promoción sub-sector hidroeléctrico, publicada en La Gaceta, Diario Oficial No 174 del 12 de septiembre del año 2012, consolidada en Digesto Jurídico 201 I, tiene por objeto promover la generación de energía utilizando fuentes hidráulicas que ayude al desarrollo social y económico del país.

Reiteramos lo que en párrafos anteriores hemos señalado, Nicaragua cuenta con un gran potencial energético de fuentes renovables, especialmente de fuentes hídricas, "se dice que su potencial hidroeléctrico, entre pequeñas y grandes cuencas hidrográficas, supera los tres mil megavatios (Milan, s.f. p.0I)", "a nivel de la región centroamericana, según la Empresa Nicaragüense de Electricidad, ENEL, Nicaragua es el país con más recursos hídricos disponibles para la generación eléctrica (Vidaurre, 2013)".

Por lo anterior, el Estado se ha visto en la necesidad de promulgar leyes y decretos específicos para promover la generación y el uso de la energía renovable en el campo de la hidroelectricidad. La Ley 467, regula como patrimonio nacional el recurso del agua, y determina que el Estado debe de garantizar su regulación y uso, priorizándolo como un recurso de consumo humano vital y necesario.

Esta ley, establece que un inversionista puede desarrollar proyectos hidroeléctricos que generen desde IMW hasta un máximo de $30 \mathrm{MW}$, a la vez regula que los proyectos hidroeléctricos que generen menos de IMWno necesitarán de permiso especial, sino que se regirán por lo dispuesto en la Ley No. 272, Ley de la Industria Eléctrica, y para proyectos superiores a los $30 \mathrm{MW}$ se requerirá de la aprobación de una ley especial. También regula de uso exclusivo del Estado de la generación hidroeléctrica en las cuentas Asturias, Apanás y Río Viejo.

Para los proyectos hidroeléctricos que generen más de un I MW hasta un máximo de $30 \mathrm{MW}$ deben de obtener un permiso de aprovechamiento de agua, el cual será emitido por la Autoridad Nacional del Agua (ANA), antes de solicitar una licencia de generación, esta última emitido por el MEM. Este permiso se otorga por un periodo mínimo de 5 años hasta un máximo de 30 años, los cuales pueden ser prorrogables, para su otorgamiento de parte de ANA se requiere la emisión del permiso ambiental de parte de Ministerio de Ambiente y Recursos Naturales (MARENA).

De lo anterior vale la pena mencionar, que el tiempo invertido en la solicitud de estos permisos entre una institución y otra puede ser extenso, el cual podría reducirse a través de la implementación de una ventanilla única cuyo objetivo sea facilitar y simplificar trámites para la formalización de solicitudes de licencias de generación, la cual estaría adscrita al Ministerio de Energía y Minas, procurando la integración de diferentes oficinas e instituciones, la cual además de reducir tiempo, también minimizaría costos, seria en palabras sencillas, una ventanilla 
homologa a la ventanilla Única de inversiones que tiene el Ministerio de Fomento, Industria y Comercio (MIFIC).

Para la promoción de los proyectos energéticos antes enunciados, la ley contempla el otorgamiento de incentivos fiscales, regulados en sus artículos 2, 3 y 4, los que tendrán un plazo de 15 años desde la promulgación de la ley. Estos incentivos fiscales son los mismos que regula la Ley No. 532, Ley para la Promoción de Generación Eléctrica con Fuentes Renovables, dirigidos al desarrollo hidroeléctrico: i) Exoneración del pago de los Derechos Arancelarios de Importación (DAl); ii) Exoneración del pago del Impuesto al Valor Agregado (IVA); iii) Exoneración del pago del Impuesto sobre la Renta (IR) y del pago mínimo definitivo del Impuesto sobre la Renta (IR); iv) Exoneración de todos los impuestos municipales vigentes, los cuales se aplicaran en igual medida que la ley 532; v) Exoneración del Impuesto de Timbres Fiscales (ITF); vi) Exoneración de todos los impuestos que pudieran existir por explotación de riquezas naturales.

Como podremos observar, la referida ley contiene disposiciones similares a las reguladas en la Ley 532, Ley para la Promoción de Generación Eléctrica con Fuentes Renovables en cuanto a los incentivos y su administración, así como en la contratación de parte de la distribuidora de la energía generada por este tipo de proyectos, y la obligación de vender al mercado de ocasión la energía cuando la empresa no mantenga contratos con la distribuidora (art. I2), además permite la exportación de energía solamente cuando la demanda interna está satisfecha, exportación que deberá de equilibrarse con el resto de proyectos de generación eléctrica de fuentes renovables.

En otro orden encontramos la Ley No 443, Ley de Exploración y Explotación de Recursos Geotérmicos, publicada en La Gaceta, Diario Oficial No 218, del 17 de noviembre del 2014, cuyo objeto es fomentar, promover y establecer las condiciones básicas relativas a las actividades de exploración y explotación de recursos geotérmicos para la generación de energía eléctrica, reiterando que estos recursos son considerados como patrimonio nacional.

"El país cuenta con 18 volcanes, de los cuales 7 están activos con un potencial superior a los I,5I9 MW (Palacios, 2016)", debido a la ubicación del país, dentro de la cordillera de los Maribios, que pertenece al cinturón de fuego del Pacífico, una de las zonas volcánicas más activas del mundo, esto quiere decir que la energía geotérmica tiene un alto potencial en Nicaragua después la Energía Hidroeléctrica, ya que representa al menos "tres veces el consumo total actual de Nicaragua, el país solo aprovecha el 10\% de su potencial geotérmico, es decir 152 megavatios. (Palacios, 2016)".

La ley 443, procura el desarrollo de la geotermia en Nicaragua, y dota de novedades al sector, ya que en el marco de las energías renovables establece de forma obligatoria la participación de ENEL en las actividades de exploración y explotación de recursos geotérmicos, y la obtención mínima del $10 \%$ de la participación accionaria de la empresa solicitante, otorgando un cargo en la junta directiva con derecho a voz y voto, convirtiendo al Estado en socio de cualquier proyecto geotérmico. Esta "participación" solo se encontraba determinada en Ley No. 286. Ley Especial de Exploración y Explotación de Hidrocarburos.

Sin embargo, esta aprobación de parte de ENEL podría generar incertidumbre, ya que el curso de la inversión en gran medida estaría en dependencia de la aceptación de esta institución gubernamental, sin conocer cuáles serían los requerimientos básicos para aprobar esta asociación, todo lo contrario, en virtud de la actualidad política del país, esto podría interpretarse como una especie de cadena política.

En el mismo sentido, el art. 3 de la ley dispone que será el MEM la institución estatal encargada del otorgamiento de las concesiones de exploración y explotación de los recursos geotérmicos, el art. 8 señala que para el otorgamiento de este tipo de concesiones será necesario obtener de 
parte de MARENA el permiso ambiental, y antes de otorgar la concesión el MEM solicitará la aprobación de los Consejos municipales correspondientes.

Esta ley faculta al Ministerio de Energía y Minas, para convocar a inversionistas nacionales o extranjeros, para que mediante negociaciones directas se pueda otorgar concesiones para la exploración y explotación de recursos geotérmicos. Además, establece el procedimiento de licitación para otorgar derechos a desarrolladores de campos geotérmicos para explorar áreas específicas de hasta 100 kilómetros cuadrados, y explotar áreas de hasta 20 kilómetros cuadrados a través de concesiones de hasta 30 años.

Los elementos esenciales que el MEM deberá tomar en consideración antes de admitir solicitud, entre otras cosas será: i) si el solicitante tiene capacidad civil, legal, técnica y financiera necesaria para la exploración o explotación de los recursos; ii) Si el área solicitada se encuentra disponible, así como los demás requisitos contemplados en la legislación, sobre todo, el cumplimiento de las medidas de seguridad ambientales.

Al igual que el resto de normas jurídicas comprendidas en el marco de las energías renovables, el Estado promueve la inversión en este sector otorgando incentivos fiscales a aquellos agentes económicos dedicados al giro de la exploración y explotación geotérmica, según lo dispuesto por la ley 532/2005 a excepción de los tributos municipales, así dispuesto en el artículo 68 de la citada ley.

Las normas jurídicas antes enunciadas las hemos considerado de especial relevancia en torno al marco regulatorio de las energías renovables, sin embargo nos parece idóneo enunciar que también existen normas jurídicas relacionadas a la generación eléctrica a través de fuentes renovables de manera indirecta, y por ello es preciso su mención:

Para el sector en general: i) Ley No. 217, Ley General del Medio Ambiente y los Recursos Naturales, consolidada por Digesto Jurídico Nicaragüense hasta el 17 de enero del 2014, publicada en La Gaceta, Diario Oficial No. 20 del 31 de enero del 20I4; ii) Ley No. 554, Ley de Estabilidad Energética, consolidada por Digesto Jurídico, publicada en La Gaceta, Diario Oficial No. 175 , del 13 de septiembre del 2012.

\section{I.2.I. Influencia de la normativa ambiental}

Así como hemos enunciado anteriormente, la legislación ambiental es un importante complemento al marco regulatorio de las energías renovables, tanto que cada uno de los proyectos de generación de energía con fuentes renovables debe de estar respaldado a través de estudios de impacto ambiental.

La principal normativa ambiental es la referida Ley No. 217, Ley General del Medio Ambiente y los Recursos Naturales, consolidada por Digesto Jurídico Nicaragüense hasta el 17 de enero del 20I4, publicada en La Gaceta, Diario Oficial No. 20 del 3 I de enero del 20I4, cuyo objeto es el establecimiento de normas para la conservación, protección, mejoramiento y restauración del medio ambiente y los recursos naturales que lo integran, asegurando su uso racional y sostenible, de acuerdo a lo señalado en la Constitución Política.

El art. 8 faculta al Ministerio del Ambiente y de los Recursos Naturales (MARENA) como ente regulador de la política ambiental del país, y como responsable del cumplimiento de la citada Ley, dentro de sus principales funciones está la de otorgar los permisos ambientales basados en los estudios de impacto ambiental realizados para cada actividad prevista en la Ley del Medio Ambiente.

En este sentido, y desde el punto de vista ambiental, todos los agentes económicos interesados en desarrollar proyectos de generación de energía con fuentes renovables deberán presentar 
con la solicitud de licencia, los estudios ambientales correspondientes, los cuales deberán cumplir con las disposiciones, normas técnicas y de conservación, según lo determine el MARENA.

Según Informe del Observatorio de Energías Renovables en América Latina y el Caribe (20l I), cada una de las solicitudes de los proyectos antes mencionados deberá de contener al menos "una descripción de los estudios de impacto ambiental a presentar, una descripción de las obligaciones sobre monitoreo ambiental, y cláusulas indicando la obligación de presentar, cuando corresponda planes de protección del medio ambiente (p.60)".

Por otro lado, el mismo informe señala que para este tipo de proyectos en materia ambiental existen importantes barreras, que deben de superarse para promover aún más el desarrollo de la energía renovable y que se convierten en necesarias para la promoción de inversiones del sector. Estas barreras fueron identificadas hace más de una década por el Programa Naciones Unidas para el Desarrollo, entre las que encontramos:

Legislación ambiental insuficiente hacia el sector energético; Debilidad en el establecimiento de normativas ambientales para el sector energía; El Sistema de Permiso Ambiental no contempla instrumentos más sencillos que la ejecución del estudio de impacto ambiental... Información no disponible o desactualizada; Dificultades en el Acceso y Divulgación de la Información.

\section{I.3. Plan Nacional de Desarrollo Humano}

Como hemos podido observar, el sub sector eléctrico se encuentra regulado por una serie de normas jurídicas que facultan al Ministerio de Energía y Minas como su ente regulador, del cual se desprende la Dirección General de Electricidad y Recursos Renovables, la cual es el órgano técnico normativo, encargado de proponer y evaluar la política del Sub sector Electricidad y Recursos Renovables; dentro de sus facultades también encontramos la de proponer las normas técnicas necesaria del sector eléctrico; promover el desarrollo de las actividades de generación, transmisión, distribución y comercialización de energía eléctrica; incluyendo la administración de las licencias y concesiones en los segmentos antes referidos de la industria eléctrica.

EL Estado de Nicaragua, a través de la publicación de su plan de buen gobierno para el corriente año 2016 estima que la generación renovable será del $52.5 \%$, así mismo, se ha comprometido en continuar y avanzar en un $48 \%$ la rehabilitación de las plantas Hidroeléctricas.

Todo los proyectos estatales antes mencionados parten del compromiso del gobierno de Nicaragua de transformar nuestra matriz energética, para que esta sea en su mayoría generada a través de fuentes renovable; compromiso que desde hace más de una década subsiste, y que en gran medida se idealizó a través del Decreto No. 13-2004 de Establecimiento de la Política Energética Nacional, publicado en La Gaceta, Diario Oficial No 175 del 13 de septiembre del 2012, a través de la cual el Estado de Nicaragua determina que el establecimiento de una política energética nacional, siendo el paso inicial y necesario para proceder al desarrollo de los planes estratégicos detallados, en los cuales se establecerán los procedimientos y las acciones necesarias para el desarrollo del sector.

Esta normativa, establece objetivos específicos que anudan al desarrollo del potencial energético renovable de nuestro país, el art.3 mandata a la utilización de las fuentes de energía limpias renovables dentro de la matriz energética nacional, asignando los recursos y los mecanismos para aprovecharlas al máximo, señalando que es obligación del Estado establecer los incentivos a las inversiones que produzcan costos aceptables, un suministro diversificado, una generación limpia y un uso eficiente. 


\subsection{Estado actual de las inversiones en del Sub Sector Eléctrico Nacional referente a energías renovables}

Constantemente, hemos resaltado el gran potencial energético que Nicaragua posee, esta particularidad no representa solo una conveniencia energética sino que también constituye una atractiva actividad económica para los inversionistas. En líneas anteriores hemos indicado que el potencial energético generado por fuentes renovables oscila entre 4,500 y $5000 \mathrm{MW}$, lo que representa muchas oportunidades de inversión.

Desde hace más de una década, el país ha atravesado por una constante transformación energética, gracias al desarrollo de inversiones públicas y privadas, especialmente en proyectos de generación energética proveniente de fuentes renovables, las que actualmente ocupan un poco más del $50 \%$ de la matriz energética, y se estima que para 2018 esta participación se eleve a "un 74 por ciento, según las últimas proyecciones oficiales (Álvarez, 2016)".

El Vice Presidente del Consejo de las Américas, Eric Farnsworth indicó que "De 2006 a 2012 Nicaragua trajo I.2 mil millones de dólares en inversiones en energías renovables en proyectos eólicos hasta geotérmicos (Espinoza, 2016)".

En el 2009 se llevó a cabo el primer proyecto eólico en el país, ubicado en el departamento de Rivas, proyecto que en sus inicios tuvo una capacidad efectiva de $40 \mathrm{MW}$ de energía a base de viento, con inversionistas privados de Guatemala, Estados Unidos y Nicaragua del denominado Consorcio Amayo, representando en ese entonces un ahorro de 30 millones de dólares en la factura petrolera anual, equivalente a 216,000 barriles de petróleo. La inversión total de este proyecto fue de 95 millones de dólares (MEM, 2009).

En la exposición de motivos de la iniciativa de ley de reforma a la Ley No. 532, Ley para la Promoción de Generación Eléctrica con Fuentes Renovables, en virtud de la cual se solicitaba la reforma del art. 8 para la extensión del termino de los beneficios fiscales, y que actualmente corresponde con la Ley No. 90I, Ley de reforma a la ley No. 532, Ley para la promoción de generación eléctrica con fuentes renovables, publicada en La Gaceta Diario Oficial No. 106 del 9 de Junio de 2015 representantes de la Presidencia de la Republica expresaron que después de la implementación del primer proyecto eólico:

En el año 2010 se amplió la capacidad de generación eólica con 23.I MW con una inversión de 48 millones de dólares; en el año 201 I se agregaron $36 \mathrm{MW}$ de capacidad efectiva geotérmica con una inversión de 223 millones de dólares; en el año 2012 se agregaron 83.6 MW de capacidad efectiva eólica con una inversión de 217 millones de dólares y $36 \mathrm{MW}$ de capacidad efectiva geotérmica con una inversión de 206 millones de dólares; para el año 2013, nueva capacidad eólica fue incorporada al Sistema con 40 MW y una inversión de 87 millones de dólares, así como $12 \mathrm{MW}$ de capacidad hidroeléctrica con una inversión de 43 millones de dólares 6 .

Respecto al sector hidroeléctrico, en el año 2015 ENEL implementó el proyecto Hidroeléctrico Larreynaga para la generación de aproximadamente $17 \mathrm{MW}$. "En los últimos 10 años, el país ha invertido alrededor de 15 millones de dólares para poner en funcionamiento 10 pequeñas centrales que generan 12,200 megavatios al año y que atienden principalmente las zonas rurales" (Vidaurre, 2013).

El Estado ha diseñado el Plan Nacional de Desarrollo Humano 20I2-20I6, en virtud del cual establece que mediante el proyecto PNESER-FODIEN, se incrementará el índice electrificación rural, a través del cual se ha llevado a cabo la generación de energía en virtud de construcción

6 Sesión de Asamblea Nacional del 21 de mayo 2015. 
de micro-represas hidroeléctricas, lo que se traduce en mejores condiciones de vida, para las familias en comunidades aisladas.

A la vez, se ha realizado la construcción de pequeñas centrales hidroeléctricas, entre las que destacan: Salto Mollejones, en El Rama (Caribe Sur), cuya capacidad es de 0.71 megavatios, seguida por La Pita Central, en El Cuá-Bocay (Jinotega), que junto a Bilampí-Musún en Río Blanco (Matagalpa), generan 0.20 megavatios cada una. En el municipio de Waslala, en el Caribe Norte, existen dos pequeñas centrales hidroeléctricas: El Naranjo y la Río Bravo, que juntas generan 0.38 megavatios. (Vidaurre, 2013)

Otro de los mayores potenciales en Nicaragua es el Geotérmico, el cual también cuenta con importantes inversiones, como evidencia de este potencial, traemos a colación el proyecto geotérmico "San Jacinto- Tizate" a través del cual entre los años 2007 y 2008 se perforaron 3 pozos geotérmicos productores, cuya potencia de generación reportada es de 12, 16 y 22.8 $M W$, resultados muy positivos a nivel de Centroamérica. Este proyecto geotérmico es ejecutado por la empresa Polaris Energy de Nicaragua S.A. (Pensa), subsidiaria de la compañía canadiense Polaris Geothermal Inc. (PGI), y tiene una capacidad instalada de 72 megavatios de energía.

Ernesto Martinez Tiffer, presidente ejecutivo de ENEL aseguró a un medio de comunicación "que toda la energía base de Nicaragua, por ese potencial inmenso que existe, debe ser geotérmico y es allí hacia dónde vamos" (Palacios, 2016).

Actualmente el campo geotérmico Momotombo, ubicado en el extremo sureste de la Cordillera de los Maribios, 55 kilómetros al noroeste de Managua, a orillas del lago de Managua y en la ladera meridional del volcán Momotombo, tiene una capacidad instalada de 70 megavatios (Palacios, 2016). Los campos geotérmicos de El Hoyo-Monte Galán y Managua-Chiltepe también han sido entregados en concesión a empresas privadas para que realicen investigaciones de exploración geocientíficas. Otros campos aptos para producir energía con el calor de los volcanes y que aún están "vírgenes" son Cosigüina, Telica-El Ñajo, Tipitapa, Masaya-GranadaNandaime y la Isla de Ometepe, en el Gran Lago (Palacios, 2016). En este sentido, en el 2014 el Gobierno de Nicaragua, y el de Islandia firmaron un acuerdo de exploración de inversiones sobre energía geotérmica con el fin de promover las inversiones en este sector.

El país también cuenta con un alto potencial solar, siendo un país tropical ubicado entre II y I4 grados al norte del Ecuador, Nicaragua dispone de una radiación global abundante recibiendo aproximadamente en promedio una radiación global de $5 \mathrm{kWh} / \mathrm{día} / \mathrm{m} 2$, siendo los departamentos de León y Chinandega los que presentan un valor superior a los $6 \mathrm{kWh} / \mathrm{dí} / \mathrm{m} 2$. (MEM, 2009), a la vez el país cuenta con fuentes ricas y diversas de biomasa con alto potencial energético.

En la guía del inversionista (2009) se establece que:

Los desechos y los productos secundarios de la producción agrícola y forestal son fuentes importantes de combustibles potenciales, y actualmente se están aprovechando tales desechos en dos ingenios azucareros en Nicaragua. El Ingenio Monterrosa y el Ingenio San Antonio suministran aproximadamente $30 \mathrm{MW}$ cada uno al sistema interconectado, con la combustión de bagazo (un producto secundario de la producción de azúcar), y del eucalipto cosechado específicamente para la producción de vapor y la generación de electricidad. El MEM y la Agencia de Cooperación Brasileña (ACB) han estimado que la cantidad de biomasa que está disponible tiene un potencial de aproximadamente $700 \mathrm{MW}$ en el corto plazo y en el largo plazo existen expectativas de ser muy superior como resultado de la sostenibilidad del recurso (p. 31 ).

El Gobierno de Nicaragua, en plan indicativo y de expansión vigente desde el 2013 ha planteado la meta de alcanzar el 90\% de la generación eléctrica con fuentes renovables para el año 2027. 
"Los proyectos eólicos, de biomasa, hidroeléctricos y solares suministraron 180 megavatios en los últimos años (Jarquín, 2016)”.

El Banco Mundial (BM), El Banco Interamericano de Desarrollo (BID), El Banco Centroamericano de Integración Económica ( $\mathrm{BCIE})$, y algunas agencias de cooperación de países como Suiza, Canadá, Noruega y Finlandia son las principales instituciones que otorgan el financiamiento para el desarrollo del sector energético, a través de fuentes renovables.

Gracias a todos los avances en este sector, y a pesar de todo lo que falta por mejorar, Nicaragua continúa situándose como ejemplo de la producción de energía eléctrica con fuentes renovables. La fundación The Climate Reality Project reconoció al país como uno de los tres países que están avanzando a nivel mundial en este sector, coadyuvando a la reducción de las emisiones de gases del efecto invernadero. Tomemos en consideración que del 2007 a la fecha, el Gobierno ha impulsado proyectos de inversión pública y privada, duplicando en este sentido el aporte de las renovables en la matriz energética nacional.

Por otro lado, en el Informe Climascopio (2015) el cual se encarga del monitoreo de las condiciones para la inversión en energía limpia conectada a la red y fuera de la red y proporciona una gran cantidad de información de las estadísticas a nivel mundial, Nicaragua descendió 13 puestos, cayendo hasta la posición 27 , comparado con el año 2014 en el que había ocupado el puesto 14.

El informe señala que este descenso se debe al desmejoramiento en los resultados obtenidos en las categorías: i) Cantidad invertida en inversiones en energía limpia y créditos para proyectos relativos al cambio climático; ii) Préstamos, donaciones, programas de donaciones; iii) Negocios de bajas emisiones de carbono y cadenas de valor de energía limpia, y iv) Actividades de gestión de las emisiones de gases de efecto invernadero.

A pesar de las diversas opiniones e informes que puedan publicarse respecto a la promoción en inversiones en materia de generación eléctrica a través de recursos renvalse, Nicaragua todavía tienen mucho por aprender en el desarrollo de este sector, es irrefutable la necesidad que tienen los inversores de revisar la viabilidad de los proyectos en energías limpias, y los gobiernos de replantear sus políticas al respecto.

\section{I.4.I Recomendaciones para una posible inversión en el Sub Sector Eléctrico Nacional referente a energías renovables}

Una vez esbozado lo anterior, no está de más mencionar que todo tipo de inversión empieza por el proceso de incorporación y registro de una sociedad en Nicaragua o bien la incorporación y registro de una sucursal, cuyo trámite es expedito y el cual se puede realizar a través de la Ventanilla Única de Inversiones (VUI), oficina adscrita al Ministerio de Fomento, Industria y Comercio (MIFIC). Esta oficina está conformada por las principales instituciones del gobierno involucradas en el proceso y provee un servicio gratuito de alta calidad para inversionistas, reduciendo el tiempo de incorporación a aproximadamente de 6 u 8 días.

Una vez que la sociedad recién constituida se encuentra lista para iniciar operaciones, es preciso iniciar los procedimientos para la obtención de los permisos necesarios y obligatorios, en el caso que nos ocupa, es idóneo que el inversionista tome en cuenta los siguientes elementos antes de decidir invertir en este sector: i) debe de revisar el plan indicativo que tiene el MEM con el fin de conocer las proyecciones planteadas por el Estado, y la necesidad de inversión según el recurso a desarrollar, es decir, se debe de verificar la planeación energética del país, ii) el otro acápite que es necesario analizar, son la banda de precios de referencias con la finalidad de proyectar el plazo de recuperación de la inversión, iii) posterior a la proyección de la inversión y con la sociedad debidamente constituida y lista para inicio de operaciones mercantiles, se debe 
proceder a obtener todos los permisos necesarios para obtener la licencia de generación a través de fuentes renovables. (J. Vásquez, entrevista personal 25 de mayo de 2016), en el caso del desarrollo de proyectos geotérmicos, la ley mandata a solicitar concesión y no licencia.

El conjunto de permisos que se deben de obtener para este tipo de proyectos se encuentran disgregados en el ordenamiento jurídico del sector, ya que dependen en gran medida del recurso natural a explotar, pero de forma general, todo agente que pretenda desarrollar proyectos de generación eléctrica con fuentes renovables debe de solicitar ante el MEM una licencia provisional, la que le permitirá la realización de estudios de factibilidad de la inversión siendo necesario determinar y estudiar las condiciones del proyecto a nivel técnico, económico, social y ambiental, esta licencia será otorgada por un plazo máximo de dos años. Además de los estudios antes enunciados, se requieren realizar estudios de impacto a la red, para verificar que el proyecto de generación a desarrollar es compatible con la red nacional y regional (J. Vásquez, entrevista personal 25 de mayo de 2016).

Cabe señalar que "el otorgamiento de una licencia provisional, no otorga al dueño de la licencia el derecho exclusivo sobre el proyecto en sí por lo que para un mismo estudio o proyecto se puede otorgar más de una licencia provisional (MEM, 2010, p. 46)".

Una vez que se cuenta con la realización de los estudios antes señalados, se puede proceder a la solicitud de obtención de licencia de generación según el recurso que corresponda.

Para la obtención de licencia de generación, es necesario cumplir además con el resto de requisitos impuestos por el MEM, para poder participar de cualquiera de los privilegios y obligaciones descritas anteriormente, ésta institución pública cuenta con un formulario para cada tipo de solicitud el cual está a disposición de los interesados en la página web del MEM, en la dirección: www.mem.gob.ni en la sección destinada a la Dirección General de Electricidad y Recursos Renovables, encontrándose también los requisitos necesarios para este tipo de proyectos, los cuales a nivel general podemos mencionar: los requerimientos legales son: i) Documentación legal que acredite la constitución de la Empresa e inscrita en el Registro Mercantil; ii) Documentación que acredite el apoderamiento del representante orgánico de la sociedad; iii) Documentos fiscales de la sociedad; iv) Permiso ambiental o autorización ambiental otorgada por el Ministerio del Ambiente y los Recursos Naturales (MARENA).

Algunos de los requerimientos técnicos son: i) Descripción general del proyecto; ii) Documentación que acrediten la capacidad técnica y experiencia de la empresa en el tipo de obras; iii) Cronograma de obras del proyecto; iv) Cronogramas de la inversión.

Algunos de los requerimientos financieros son: i) Acreditación de la capacidad financiera de la Empresa para realizar las obras; ii) Estados financieros de los último $s$ tres (3) años, como mínimo, debidamente auditados; iii) Modalidad de financiamiento, si es a través de recursos propios o a través de préstamos.

Entre otros muchos más, de carácter específico que dependerán del recurso a desarrollar, si es geotérmico recordemos que el Estado deberá tener una participación del $10 \%$ de las acciones, por lo que habrá que establecer un acuerdo de asociación, y otros requerimientos propios para el recurso hidroeléctrico o eólico, etc.

Cabe señalar que toda la información debe ser presentada en el idioma español. Cualquier documento que no esté en el idioma español debe ser traducido a este idioma. La documentación de la solicitud debe ser sometida en un original y tres copias.

Es necesario señalar que la mayoría de los proyectos de esta envergadura provienen de inversionistas extranjeros, inversión que según nuestra carta marga el Estado debe de asegurar 
a fin de contribuir con el desarrollo económico y social del país (art. $100 \mathrm{Cn}$ ). Siendo así, es importante delimitar el procedimiento antes referido, por ello el Estado debe de ser el principal garante de la seguridad jurídica, ejecutando negociaciones transparentes y priorizando la seguridad y estabilidad del país y sus ciudadanos.

\section{Sistema jurídico del Sub Sector Eléctrico en Guatemala}

Las energías renovables no contaminan, no consumen, ni agotan los recursos naturales. 100\% Energía Limpia. Asociación de Generadores con Energía Renovable de Guatemala.

\section{I Contexto Nacional Guatemala}

Guatemala, es uno de los países más grandes de la región centroamericana, el Banco Mundial (2016) considera que éste país ha tenido uno de los mejores desempeños económicos de América Latina, con una tasa de crecimiento por encima de 3 por ciento desde 2012 y alcanzando cerca de 4 por ciento en 2015. Sin embargo, a pesar de este avance económico, Guatemala fue uno de los pocos países que presentó un fenómeno de aumento de pobreza, pasando del $51 \%$ en el 2006 a 59.3\% en el 2014. Así mismo, indicó que según sus proyecciones si el país logra crecer al menos un $5 \%$ anual por los próximos años.

Actualmente la mayor generación de energía en Guatemala es proporcionada por fuentes renovables con un 63.5I \% del total de la generación (MEM, 2016). Para el mes marzo de este año, la matriz de generación eléctrica por tipo de combustible era de: $33.98 \%$ de Biomasa, $23.92 \%$ Hídrica, 22.42\% de Carbón, $14.07 \%$ de bunker, $2.78 \%$ Geotérmica, I.61\% solar, I.16\% eólica, $0.06 \%$ biogás. (MEM, 2016. p.03).

Para el año 2014, el índice de cobertura eléctrica se registró en un 90.20\%, (MEM, 2016), y el porcentaje de capacidad instalada del parque generador del sistema nacional interconectado por tipo de propiedad al mes de marzo del 2016 corresponde al $85.08 \%$ de propiedad privada, y $14.92 \%$ de propiedad estatal, lo que claramente refleja la disponibilidad que tiene el país a la apertura a inversiones en este sector.

Rafael Alvarado, socio del despacho jurídico Consortium Legal en Guatemala ha expresado:

La inversión privada, tanto nacional como extranjera en la generación de energía con fuentes renovables ha crecido exponencialmente a raíz de la posibilidad de interconexión y venta de energía en el mercado mayorista. Esto ha permitido que aumenten los proyectos hidroeléctricos y mejoras en cuanto a la capacidad de ingenios y procesadoras de caña de azúcar para generar y vender energía como un método alternativo para generar ingresos.

En este sentido, el portal web del Ministerio de Energía y Minas de Guatemala ha publicado que la inversión en el sector ha sido cuantiosa, a modo de ejemplo, el Banco Interamericano de Desarrollo (BID) ha otorgado US\$ 500,000.00 para el Programa de Apoyo a la Gestión Ambiental y Social para el Fomento a la Participación Privada en el Desarrollo de las Fuentes Renovables de Energía en Guatemala; cuyos componentes son: i)Evaluación estratégica de los aspectos ambientales y sociales de proyectos hidroeléctricos, ii) Apoyo a la formulación de políticas, iii) Apoyo al sistema de información geográfico y difusión y iv) Comunicación estratégica.

En la misma página web se informa que la Agencia Japonesa de Cooperación Internacional-JICA financia el proyecto Promoción de Actividades Productivas con el uso de Energía Limpia en Aldeas del Norte, siendo el monto de la donación aproximadamente de US\$II millones de dólares. 


\subsection{Marco institucional y jurídico del Sub Sector Eléctrico en Guatemala}

Águila (2005, p.04) indica que:

Guatemala es uno de los pioneros del subsector eléctrico de Centroamérica puesto que en 1884 fundó la Empresa Eléctrica de Guatemala Sociedad Anónima (EEGSA), bajo una concesión emitida por el estado para producir y distribuir electricidad. En 1959 se crea el Instituto Nacional de Electrificación INDE, como entidad descentralizada del estado responsable de generar, transportar y distribuir la energía eléctrica.

EI INDE tenía la responsabilidad de hacerse cargo de toda la generación, transporte y distribución eléctrica del país, con estructuras verticalmente integradas en generación, transporte y distribución de energía eléctrica (Águila, 2005).

Mucho tiempo después, al iniciar la década de los noventa, el sub sector eléctrico se vio afectado por una serie de reformas que fueron la consecuencia de los procesos acontecidos en virtud de la crisis energética de la época (BCIE, 20I0).

Con la finalidad de contribuir al desarrollo productivo del país propiciando la disponibilidad de energía eléctrica de la manera más económica en todas las regiones del país, y con la necesidad de incrementar la cobertura eléctrica, mejorar la calidad del servicio eléctrico y optimizar la oferta y el uso de la misma, preservando el equilibrio ecológico, en 1996 se estableció una reforma al marco regulatorio para el subsector eléctrico, para lo cual se emitió la Ley General de Electricidad (Águila, 2005).

Con las reformas antes mencionadas, se implementaron políticas de apertura a la participación del sector privado, es decir, concretando los primeros negocios de generación con la participación de inversionistas privados, cuya consecuencia ha sido el desarrollo de las inversiones previamente enunciadas (MEM, 2006).

Derivado de ésta reforma se estableció una nueva estructura a partir de la segmentación de la industria eléctrica en cuatro actividades principales: generación, transmisión, comercialización y distribución. Además se procedió a la privatización de la mayoría de la distribución y en forma parcial la generación (Asociación Nacional de Generadores, 20I2).

\section{La Asociación Nacional de Generadores, ha publicado (2012) que esta reforma y}

La estructura implementada en el subsector eléctrico tiene por objetivo promover la participación privada, fomentar la competencia y los mecanismos de mercado, estimular el incremento del sector eléctrico, aumentando la oferta, la demanda y la cobertura eléctrica, al tiempo que se reduce la participación del Estado en el subsector.

Desde entonces, el país cuenta con una estructura institucional ordenada y efectiva, la cual involucra la participación de una diversidad de sujetos, que mantienen la operatividad del sector, sus principales instituciones son: i) Ministerio de Energía y Minas (MEM), ii) la Comisión Nacional de Energía Eléctrica, iii) Administrador del Mercado Mayorista, y iv) los generadores, los transportistas, los distribuidores, y los comercializadores (MEM, 2006).

El Ministerio de Energía y Minas, como órgano rector del sector, es la entidad encargada de elaborar las políticas y planes indicativos de generación, le corresponde atender lo relativo al régimen jurídico aplicable a la producción, distribución y comercialización de la energía y de los hidrocarburos, así como la explotación de los recursos mineros; además debe de procurar el aprovechamiento de los recursos naturales del país, propiciando el desarrollo sostenible de la nación. El MEM también se encarga de otorgar las autorizaciones para la instalación de centrales 
generadoras y para prestar los servicios de transporte y distribución final de electricidad. (MEM, 2014).

Además de las funciones antes señaladas, el MEM debe de elaborar informes de evaluación socioeconómica con el fin de determinar el costo y viabilidad de proyectos de electrificación rural, a través del Instituto Nacional de Electrificación (INDE), además debe de inscribir y actualizar a los Grandes Usuarios y Agentes del Mercado Mayorista, promover el desarrollo de proyectos de energía renovable y calificar proyectos de fuentes renovables de energía, al amparo de la Ley de incentivos (MEM, 20I4).

La Comisión Nacional de Energía Eléctrica (CNEE), es configurada por la Ley General de Electricidad, como el ente regulador del sistema, el cual debe de cumplir y hacer cumplir la Ley y sus reglamentos, e imponer las sanciones a los infractores, velar por el cumplimiento de las obligaciones de los adjudicatarios y concesionarios, proteger los derechos de los usuarios y prevenir conductas atentatorias contra la libre empresa, como una de sus principales funciones se encuentra la de definir las tarifas de transmisión y distribución, así como la metodología para el cálculo de las mismas.

Además, deberá de dirimir las controversias entre los agentes del subsector eléctrico actuando como árbitro entre las partes cuando éstas no hayan llegado a un acuerdo. Al mismo tiempo deberá de emitir las normas técnicas relativas al subsector eléctrico y fiscalizar su cumplimiento; también deberá de emitir las disposiciones y normativas para garantizar el libre acceso y uso de las líneas de transmisión y redes de distribución (MEM, 20I4).

El Administrador del Mercado Mayorista, es la entidad encargada de la operación del SIN y de administrar las transacciones, fue configurada como una entidad privada sin fines de lucro, que coordina las transacciones entre los participantes del Mercado Mayorista, cuyas funciones principales son la coordinación de la operación de centrales generadoras, interconexiones internacionales y líneas de transporte; también debe de determinar los precios de mercado de corto plazo para las transferencias de potencia y energía entre sus agentes, rigurosamente debe de velar por la seguridad y el abastecimiento de energía eléctrica en el país, así como la de crear las disposiciones generales para la operación de los agentes del mercado mayorista.

Según el artículo 6 de la Ley General de Electricidad son Agentes del Mercado Mayorista: Los generadores, comercializadores, distribuidores, importadores, exportadores y transportistas. A la fecha se encuentran inscritos en el MEM, 45 agentes generadores, 32 agentes comercializadores, 10 agentes transportistas y cuatro agentes distribuidores (MEM 20I6).

En el caso de los generadores, el reglamento de la LGE los define como: la persona, individual o jurídica, titular o poseedora de una central de generación de energía eléctrica, que comercializa total o parcialmente su producción de electricidad y deben tener una potencia máxima mayor de cinco megavatios (5 MW). (Luna, 20I4).

En el caso de los transportistas, estos son definidos en la LGE y su reglamento como: La persona, individual o jurídica, poseedora de instalaciones destinadas a realizar la actividad de transmisión y transformación de electricidad, la cual deben tener capacidad de transporte mínima de diez megavatios (I0 MW) (Luna, 2014).

La LGE y su reglamento definen a un comercializador como: La persona, individual o jurídica, cuya actividad consiste en comprar y vender bloques de energía eléctrica con carácter de intermediación y sin participación en la generación, transporte, distribución y consumo, deben de comprar o vender bloques de energía asociados a una oferta firme eficiente o demanda firme de por lo menos dos megavatios (2 MW) (Luna, 20I4). 
En lo que respecta al marco legal, la Comisión Nacional de Energía Eléctrica ha publicado en su portal web (http://www.cnee.gob.gt) un compendio de leyes y reglamentos correspondiente al marco legal del sub sector eléctrico de Guatemala, y entre sus principales normas jurídicas encontramos: i) Constitución Política de la República de Guatemala, ii) Ley General de Electricidad Decreto No. 93-96 y Reglamento a la Ley General de Electricidad-Acuerdo 256-97,; iii) Reglamento del Administrador del Mercado Mayorista -AMM- Acuerdo 299-98, iv) Ley de Incentivos para el Desarrollo de Proyectos de Energía Renovable y su Reglamento, así como las Normas Técnicas de Transmisión y Distribución, Normas de Coordinación Comercial y Operativa y procedimientos técnicos que complementan el marco regulatorio.

La Constitución Política de la República de Guatemala, en su art. 64 declara de interés nacional la conservación, protección y mejoramiento del patrimonio natural de la Nación, obligando al Estado al fomento y creación de parques nacionales, reservas y refugios naturales, los cuales son inalienables.

En torno a la utilización de los mismos, el art. I 8 regula los principios que deben de enmarcar el régimen económico y social de la nación, obligando al Estado a orientar su economía para lograr la utilización de los recursos naturales procurando un incremento en las riquezas, generando empleo y la equitativa distribución del ingreso nacional.

En el art. 129 declara de urgencia nacional, la electrificación del país, sobre las bases de los planes formulados por el Estado y las municipalidades, incentivando la participación de la iniciativa privada.

Derivada de los principios constitucionales se promulga la Ley General de Electricidad, Decreto No. 93-96, la que tiene por objeto normar el desarrollo del conjunto de actividades de generación, transporte, distribución y comercialización de electricidad.

Esta Ley enuncia cuatro principios que deberán regir el sector eléctrico: i) Es libre la generación de electricidad y no se requiere para ello autorización o condición previa por parte del Estado, más que las reconocidas por la Constitución Política de la República de Guatemala y las leyes del país; ii) Es libre el transporte de electricidad, cuando para ello no sea necesario utilizar bienes de dominio público, iii) También, es libre el servicio de distribución privada de electricidad, el transporte de electricidad que implique la utilización de bienes de dominio público y el servicio de distribución final de electricidad, estarán sujetos a autorización, iv) Son libres los precios por la prestación del servicio de electricidad, con la excepción de los servicios de transporte y distribución sujetos a autorización. Las transferencias de energía entre generadores, comercializadores, importadores y exportadores que resulten de la operación del mercado mayorista, estarán sujetos a regulación en los términos a que se refiere la presente ley.

La Corte Constitucional de la República de Guatemala ha publicado en La Gaceta Jurisprudencial No. 76, expedientes acumulados No. 1932-2004 y 2 157-2004, sentencia: 12-04-2005, citado por la Comisión Nacional de Energía Eléctrica en los cuales sostiene que:

La finalidad de la Ley, es propiciar la producción, transmisión y distribución de electricidad, optimizar el crecimiento del subsector eléctrico, así como descentralizar y desmonopolizar los sistemas de transmisión y distribución de energía eléctrica para agilizar el crecimiento de la oferta y satisfacer las necesidades sociales y productivas de los habitantes de la República.

Más adelante, a partir del art. 7 y siguientes se regula, que a pesar de lo antes señalado, para la generación y para utilizar los que sean bienes del Estado se requerirá de la respectiva autorización del MEM, cuando la potencia de la central exceda de $5 \mathrm{MW}$. El plazo máximo de dicha autorización no podrá exceder los 50 años. 
La generación de energía eléctrica y el suministro de la misma para la población del país, debe entenderse como una función del Estado y no como una función del sector privado o el sector municipal, de esa cuenta resulta totalmente lógico que dicha generación y suministro deba ser regulada por el MEM (Luna, 20I4).

El art. 3 de la referida norma jurídica, designa al Ministerio de Energía y Minas (MEM) como ente rector del subsector eléctrico, y a la Comisión Nacional de Energía Eléctrica (CNEE) como entre regulador. Define la figura del Administrador del Mercado Mayorista, a quien le corresponde además la función de despacho, y permite a los generadores privados participar en la exportación de energía.

La ley regula además de lo antes señalado, las generalidades del sector, el otorgamiento de autorizaciones para cada una de las actividades del sub sector eléctrico, requisitos y procedimientos que el interesado debe de cumplir, así como la operación y explotación de las centrales generadoras, sistema de transporte y distribución, causales de terminación del plazo de autorización, el régimen de precios, y el régimen de sanciones.

El Reglamento de la Ley desarrolla a mayor grado lo establecido en la LGE, procurando su correcta aplicación; establece definiciones, funciones específicas, requisitos de solicitudes y gestiones administrativas entre otras cosas.

Un acápite novedoso del reglamento, es que introduce la modalidad de generación distribuida, que permite que centrales de generación con recursos renovables cuya potencia no exceda $5 \mathrm{MW}$ se conecten a instalaciones de distribución.

En este caso se obliga a los distribuidores a conectar a sus instalaciones los proyectos de fuentes renovables, plantas menores a 5 MW. Los Generadores Distribuidos Renovables (GDR) podrán vender su generación a un Distribuidor o comercializador, los costos de interconexión del proyecto renovable al punto de conexión corren por cuenta del GDR. Esta actividad a mayor profundidad se encuentra regulada por la norma técnica CNEE I7I-2008 42 (Luna, 20 I4).

En torno al Reglamento del Administrador del Mercado Mayorista, éste establece los mecanismos de financiamiento y el funcionamiento del Administrador del Mercado Mayorista, así como las definiciones, mecanismos de verificación, el despacho económico y el cálculo de precios, la coordinación de la operación en el mercado mayorista, la administración de las transacciones en dicho mercado, y los precios y costos a trasladar a las tarifas de distribución.

La principal fuente de financiamiento del Administrador del Mercado Mayorista es la cuota que cada agente generador, transportista, distribuidor, comercializador y gran usuario participante que realiza transacciones en el mercado mayorista, paga mensualmente a dicha entidad.

Respecto a las Normas Técnicas emitidas por la Comisión Nacional de Energía Eléctrica, es preciso indicar que son autorizadas por la LGE al regular que "se deben emitir normas técnicas y disposiciones relativas al subsector eléctrico, para garantizar el libre acceso y uso de las líneas de transmisión y redes de distribución del Sistema Eléctrico Nacional” (art. 4 LGE).

Ahora bien, en lo que respecta a la Ley de Incentivos para el Desarrollo de Proyectos de Energía Renovable, promueve el desarrollo y aprovechamiento efectivo de los recursos energéticos renovables que permita a mediano y largo plazo alcanzar un desarrollo continuo de estos recursos.

El art. I de la ley declara de urgencia e interés nacional el desarrollo racional de los recursos energéticos renovables, facultando al órgano competente, es decir, al MEM para la estimulación, 
promoción y facilitación de las condiciones adecuadas para el fomento de inversiones que desarrollen proyectos de energía renovable.

En su art. 2 establece que su objeto será promover el desarrollo de proyectos de energía renovable y establecer los incentivos fiscales, económicos y administrativos para el efecto. Los incentivos operarán de acuerdo a la fase en la que se encuentre el proyecto de energía renovable, es decir que, dicha ley establece tres períodos para gozar de los incentivos; el período de pre inversión; el período de ejecución y el período de operación, por ello dependiendo del período en que se encuentre el proyecto se podrá optar a los incentivos fiscales (Luna, 20I4).

EL artículo 5 de la Ley de Incentivos contempla lo siguiente: i) Exención de derechos arancelarios para las importaciones, incluyendo el Impuesto al Valor Agregado -IVA-, durante el período de reinversión y el período de construcción; ii) Exención del pago del Impuesto Sobre la Renta; iii) Exención del Impuesto a las Empresas Mercantiles y Agropecuarias -IEMA-. En todos los casos el período de máximo para disfrutar de la exoneración será de 10 años.

La ley es escueta y posee artículos similares a la nuestra, sin embargo el art. 7 de la misma, manda a emitir el correspondiente reglamento a la ley que permita la calificación y aplicación concreta de los incentivos correspondientes.

En virtud de lo anterior, el reglamento a la ley de incentivos para el desarrollo de proyectos de energía renovable, tiene por objeto establecer las condiciones adecuadas para la calificación y aplicación concreta de los incentivos establecidos en la referida Ley.

A partir del capítulo tres del reglamento, se estipulan los requisitos y condiciones que debe de cumplir el interesado para hacer uso de los incentivos contemplados en la norma, regula lo concerniente a los trámites de la solicitud, los procedimientos específicos, las obligaciones de los titulares, la fiscalización de los proyectos, los procesos administrativos.

Es importante resaltar que desde el punto de vista procedimental los requisitos y el trámite del procedimiento para la solicitud de generación en Guatemala se encuentra detallado de forma general en las normas jurídicas y todo aquello que no se encuentra contemplado en la ley se encuentra regulado en el Manual para el Trámite de Solicitudes de Autorización para Utilización de Bienes de Dominio Público para la Instalación de Centrales Generadoras, es así que según el artículo 7 del Reglamento de la Ley General de Electricidad (RLGE), se podrá otorgar una autorización temporal, a solicitud de cualquier interesado, para el estudio de obras de transporte y transformación de energía eléctrica que requieren la autorización, para la realización de obras de generación, El plazo máximo de la autorización temporal será de un año.

En resumidas palabras la solicitud para la Autorización Temporal para uso de Bienes de Dominio Público es presentada ante la Dirección General de Energía (DGE), la cual podrá requerir aclaraciones o ampliaciones a los interesados, relacionadas con la documentación técnica presentada. Dicha solicitud se notificará por escrito, dando un plazo perentorio para las aclaraciones, posteriormente la DGE elaborará el dictamen técnico correspondiente, en el cual incluirá: a) pronunciamiento sobre la procedencia o no de la solicitud, con base en el análisis técnico realizado; $y$ b) en caso no procediera la solicitud, se deberá hacer un pronunciamiento razonado sobre la existencia de los problemas técnicos por los cuales ésta se descalificó.

Posteriormente, el Ministerio de Energía y Minas (MEM) emitirá el Acuerdo respectivo, sobre si procede la autorización. En caso contrario, se emitirá la Resolución Ministerial que deniega la solicitud, notificándole en ambos casos al interesado.

Cabe resaltar que según el recurso a explotar deberá de cumplirse con requisitos adicionales y variaciones en su procedimiento. 
Habiendo descrito brevemente las cualidades legislativas e institucionales de Guatemala en relación al sub sector eléctrico en energías renovables, es importante destacar los elementos de éxito que ha desarrollado este país.

Guatemala se encuentra en la posición de liderazgo de electrificación rural después de Costa Rica, al menos a nivel regional y la misma tiene al menos un $80 \%$ de inversión privada en el sub sector eléctrico de energía renovable, en este sentido, la Asociación Nacional de Generadores ha publicado (2015) que éste logro no solamente es causado por una buena ley, sino que se debe en gran medida a un compromiso institucional, de parte del Ministerio de Energía y Minas de establecer la responsabilidad de cumplir a cabalidad las atribuciones que la Ley le define de dictar las políticas energéticas, así como respetar las funciones de las otras instituciones del sector y sobre todo como institución ha evitado efectuar cambios constantes a los reglamentos (Asociación Nacional de Generadores, 2015).

De parte de la Comisión Nacional de Energía Eléctrica su compromiso se ha enfocado en vigilar el cumplimiento del marco regulatorio, estableciendo tarifas a través de una formulación técnica, ha sido una institución facultada para aprobar o improbar cambios normativos pero limitada para efectuarlos; por parte del Administrador del Mercado Mayorista, como institución de índole privada se han convertido en los responsables de la operación y liquidación del mercado, con pluralidad de sujetos ( 10 directores, dos por cada tipo de Agente del Mercado) que conlleva a un control cruzado, y permite ser una entidad técnica, altamente calificada (Asociación Nacional de Generadores, 2015).

Además del compromiso institucional, el éxito de este país se debe a la estabilidad regulatoria, ya que no ha habido modificaciones a la Ley General de Electricidad en 19 años, a lo largo de 5 gobiernos, solamente ha existido una reforma al reglamentos de la Ley en el año 2007; lo que tiene como consecuencia certeza jurídica, existiendo libre competencia, sin ningún tipo de privilegios. Con todo el éxito alcanzado, Guatemala sigue siendo un país con muchos retos, sin embargo cuanta con el potencial y los elementos para seguir posicionándose y liderar el sector (Asociación Nacional de Generadores, 2015).

Las normas jurídicas y técnicas de la mano de instituciones comprometidas con el sector, son la perfecta combinación que ha hecho Guatemala para propiciar la inversión en el sector

"Las energías renovables contribuyen a disminuir la dependencia de nuestro país de los suministros externos, aminoran el riesgo de un abastecimiento poco diversificado y favorecen el desarrollo tecnológico y la creación de empleo" Asociación de Renovables de Nicaragua.

\section{Oportunidades de mejoras al sub sector eléctrico de energías renovables}

Según el Plan estratégico 201 I-2015 elaborado por la Asociación Renovables de Nicaragua, el país cuenta con la capacidad de generación de electricidad más baja de Centroamérica y con el menor porcentaje de la población a su acceso, además cuenta con un alto porcentaje de dependencia de los recursos fósiles para la generación de la misma.

En este sentido, la generación de electricidad con fuentes renovables juega un rol importante, por el potencial de recursos naturales con los que se cuenta, es decir, Nicaragua tienen el potencial de satisfacer el $100 \%$ de sus necesidades de electricidad con energía renovable, siempre y cuando cuente con las políticas, incentivos y apoyo político apropiado para impulsar y desarrollar este sector.

La importancia de fortalecer el desarrollo de proyectos de generación eléctrica a través de fuentes renovables implica la posibilidad de alcanzar altos niveles de electrificación rural, la 
disminución de nuestra dependencia de los recursos fósiles, y la contribución no solo al desarrollo económico y social del país, sino además al cambio climático.

Dolezal, Majano, Ochs y Palencia (2013), sostienen que la inversión en energía renovable está fuertemente influenciada por el clima de inversión de un país. El ambiente de negocios determina no solo el nivel de la inversión, sino el costo del capital y los servicios relacionados. Nicaragua de forma general ha facilitado un marco emergente de políticas de apoyo a este sector. Sin embargo, el principal desafío es fomentar un ambiente que permita al inversionista evaluar y manejar el riesgo, en este sentido, los procedimientos burocráticos, costosos y prolongados son uno de los principales obstáculos para el desarrollo de este sector.

Dolezal, et al (2013, p.59) también han señalado que:

La experiencia internacional sugiere que los países que ha promovido exitosamente el desarrollo y el uso de la energía renovable cuentan con tres componentes básicos y esenciales de políticas: una visión de energía a largo plazo que incluye metas, objetivos, políticas y medidas concretas para lograr esta visión y estructuras y procesos administrativos eficaces.

El gobierno de Nicaragua en reiteradas ocasiones ha anunciado sus planes de alcanzar para el 2027 el $90 \%$ de la generación eléctrica a través de fuentes renovables, sin embargo, estos planes carecen de claridad sobre metas específicas, es decir, las rutas para lograr estas metas no han sido publicadas o no existen.

A pesar de los éxitos que el país ha sostenido respecto al incremento de inversión en este sector, todavía existen muchas barreras institucionales y la transparencia en políticas que complican el aprovechamiento del pleno potencial nacional. Dolezal señala que uno de los obstáculos más notables no solamente a nivel nacional, sino a nivel regional es tiempo que requiere procesar "una evaluación ambiental, la aprobación de permisos de construcción y la obtención de beneficios tributarios para los proyectos de energía renovables" (20I3. P.6I).

Dicho lo anterior, vale la pena traer a colación lo señalado en la Conferencia Internacional sobre Energía Renovable, celebrada en Bonn, Alemania en el año 2004:

Para que las políticas logren acelerar la energía renovable deben ser "fuertes, duraderas y legales". "Duraderas" se refiere a la necesidad de una visión a largo plazo que guíe la acción política muy adelante en el futuro y que dure más que cualquier cambio de líderes políticos... "Fuertes" pone de relieve la importancia de los objetivos y políticas de energía renovable... y comprometen a todos los interesados a avanzar hacia una misma meta. "Legales" indica la necesidad de poner por escrito una visión amplia de energía que incluya metas y objetivos globales, a fin de que sea accesible para cualquier parte interesada y garantizar que las leyes y objetivos de energía renovable sean obligatorios y aplicables (Dolezal, 2013, p.59).

\section{I. Perspectivas y recomendaciones para avanzar en materia de energía renovables}

Una de las mayores recomendaciones para el fortalecimiento del marco jurídico y regulatorio de la energía renovable, en virtud del cual se puedan concretizar condiciones idóneas para el desarrollo de la generación eléctrica a través de la diversidad de fuentes renovables con las que en la actualidad cuenta el país, un marco jurídico regulatoria que describa de forma eficaz y sin contradicciones los requisitos, procedimientos, sanciones, tarifas, incentivos, en fin, todo lo relativo a la regulación y promoción de las renovables. 
Analizando el panorama, en Nicaragua la generación de energía, a través de fuentes renovables resulta una necesaria y atractiva actividad económica, ya que inversiones de esta envergadura son capaces de atraer importantes cantidades de dinero al país, sin embargo, la principal desventaja que el desarrollo de este sector presenta es la carencia de una estructura normativa equilibrada que establezca de forma clara y transparente los procedimientos de implementación y requerimientos de operación para el desarrollo de este tipo de proyectos.

No debemos olvidar que el estricto cumplimiento de la norma jurídica debe ser el límite de actuación de las entidades gubernamentales y sus funcionarios, en el caso de Nicaragua, el MEM debe de someter sus actuaciones a las leyes, cumpliendo con el principio de legalidad y no a la aplicación de normativas específicas de menor rango.

Otra de las recomendaciones que proponemos con el fin de avanzar en este sector implica acelerar y simplificar los procedimientos administrativos, la diversidad de permisos entre instituciones diferentes, en gran medida complica y hace poco atrayente la inversión, consumen tiempo y dinero.

La simplificación de estos procedimientos, puede ser compleja debido a la falta de integración de las principales instituciones gubernamentales, en este sentido, al inicio de este estudio propusimos la creación de una "ventanilla única" para que el procedimiento de obtención de permisos se acelerara y simplificara, ya que esta herramienta puede ayudar a disminuir la carga administrativa y aminorar la burocracia existente.

"Estas ventanillas únicas aumentan la tasa de implementación exitosa de proyectos a través de la colaboración activa entre el sector privado y e instituciones gubernamentales, aumentando el atractivo a nuevas inversiones en energía renovable (Dolezal, 2013. p. 77)".

Por ultimo, pero no menos importante, se recomienda establecer metodos de medicion, es decir, la meta que se ha impuesto el gobierno de generar el $94 \%$ de la matriz energética a traves de fuentes renovables, debe de estar en constante medicion, con el fin de evaluar su progreso, lo que conlleva a un necesario monitoreo, y constante revisión y verificación de las políticas implementadas.

Por otro lado, pero en el mismo sentido la Asociación Renovables de Nicaragua, propone una iniciativa de reforma a la ley 532, tomando en cuenta los siguientes aspectos: que se establezcan incentivos fiscales, económicos, administrativos y financieros para el efecto de nuevos proyectos con fuentes renovables, ampliaciones a la capacidad instalada de los proyectos de generación eléctrica en operación, mejoras de la eficiencia en equipos y procesos que causan el aumento de producción de energía y mejoras para mantener el recurso renovable, todo esto no solo a grandes proyectos. Véase también el informe ${ }^{7}$ para conocer otras reformas a nivel técnico que por la amplitud de la materia no podemos abordar.

Seria idóneo crear un sistema que incentive la utilización de generación distribuida, similar al de Guatemala la cual vendría a incentivar la inversión de proyectos a pequeña o mediana escala que contribuirían con la economía y con el desarrollo social, capaces de implementar altos estándares en tecnología que procuren un mayor aprovechamiento del recurso natural y menos perdidas energéticas, para ello deben de realizarse estudios a nivel de regulación y a nivel de implementación de los sistemas, debiéndose especificar las características fundamentales como el tamaño, tecnología, tarifas de compraventa, estructuras contractuales, etc.

Además de lo mencionado anteriormente, es importante señalar que en el marco de una posible reforma que procure una modificación estructural en materia de incentivo a la generación a través de fuentes renovables, podría considerarse establecer procesos de licitación, minimizando

7 http://www.renovables.org.ni/media/Documentos/Marco_Legal_-_presentacion_03-05-12.pdf 
las actuales contrataciones directas, con el fin de determinar aquellos proyectos sólidos y con las cualidades y características que el país demande.

En Nicaragua, una posible reforma normativa a nivel estructural favorecería el dialogo entre las instituciones gubernamentales y actores de los proyectos, sean grandes 0 no, con el fin de consensuar un equilibrio normativo y resolver barreras percibidas en relación al tema de obtención de permisos y tramitación de licencias para proyectos de energía renovable, así como el aprovechamiento de los incentivos ya descritos.

Martin Schaffer, Gerente Comercial de ICPower opina que "lo que está faltando ahora es voluntad Política para seguir incentivando estas energías, ya que existen proyectos sobre los que se han realizado estudios y simplemente el gobierno no nos da la licencia...tampoco la niega, simplemente hacen silencio" (Entrevista personal 09 de agosto de 2016).

Habiendo señalado lo anterior, esperamos que lo aquí contemplado, y la reforma propuesta por la Asociación de Renovables de Nicaragua, sea tomada en consideración, todo con el único fin de establecer una mentalidad de nación en torno a la promoción y desarrollo de proyectos de generación de energía a través de fuentes renovables.

\section{Conclusiones}

El sub sector eléctrico en materia de energías renovables se encuentra en estado de crecimiento, considerando que están en desarrollo varios proyectos de energías renovables que apuntan a una importante transformación de la matriz energética, sumado al Programa Nacional de Electrificación Sostenible y Energía Renovable (PNESER), más el desarrollo de casos exitosos como la central geotérmica San Jacinto Tizate, el cual se ha convertido en modelo de inversión en este sector.

La transformación energética antes del 2030 solo se logrará con el desarrollo de políticas duraderas, fuertes y legales que procuren el compromiso de todas las instituciones del gobierno, y en el marco de una estrategia común para el desarrollo de este sector.

El dialogo multisectorial (gobierno, empresas, asociaciones, bancos nacionales y multilaterales, organizaciones no gubernamentales, universidades, etc.) es crucial para continuar mejorando el marco regulatorio; éste debe de proyectarse al establecimiento de mecanismos para la reducción de riesgos en fase de factibilidad y a la ejecución de proyectos de energías renovables, sostenibilidad ambiental y reducción de procedimientos administrativos.

Analizar la ley en su conjunto, no hacerle más remiendos y garantizar a los inversionistas y a todos los interesados la promoción en inversión de energía renovable es el punto clave dentro del marco de una futura reforma, la implementación de un reglamento en el cual se describa de forma clara y precisa el procedimiento para la obtención de las licencias provisionales, licencias de generación o concesiones para la generación de energía con fuentes renovables, procurará seguridad jurídica, y se estaría cumpliendo con el principio de legalidad.

La promoción a la inversión en torno a este tipo de proyectos tiene como punto de partida el plan de expansión, sin embargo, el Gobierno de Nicaragua necesita realizar estudios de pre factibilidad en este tipo de inversiones, de esta manera, escogeríamos los proyectos de generación eléctrica con fuentes renovables que el país realmente necesita (Geotérmicos o hidráulicos), de esta manera se estaría minimizando los riesgos a esta inversión a través de procedimientos de licitación y menos a través de las negociaciones directas, evitando lo sucedido con proyectos como Tumarín, es decir, es necesario una planificación de inversiones en este sector. 
La implementación de una ventanilla única para este tipo de proyectos vendría a reducir los tiempos para la obtención de los diversos permisos administrativos necesarios para el desarrollo de estas inversiones, de ser posible, unificaría no solo criterios gubernamentales, sino que además sería altamente atractivo para los inversionistas, ya que al reducir tiempos, se reducen costos.

Reiteramos que el apostar por el desarrollo de las energías renovables para un país como el nuestro, solamente significa desarrollo sostenible a largo plazo, oportunidades de inversión diversas y abundantes, ya que somos un país que cuenta con un marco regulatorio en marcha y con amplias oportunidades de mejora que al final se traducen en unas necesidades que deberían observarse desde una perspectiva de nación.

\section{Referencias bibliográficas}

Acuerdo Gubernativo No 256-97. Reglamento de la Ley General de Electricidad, publicado en La Gaceta, Diario Oficial del 2 de abril de 1997, con sus reformas integradas. Recuperado de http://www.cnee.gob.gt/pdf/marcolegal/LEY\%20GENERAL\%20DE\%20ELECTRICIDAD\%20Y\%20REGLAMENTOS.pdf

Acuerdo Gubernativo No 299-98. Reglamento del Administrador del Mercado Mayorista, publicado en La Gaceta, Diario Oficial del I de junio de 1998, con sus reformas integradas. Recuperado de http://www.cnee.gob.gt/pdf/marcolegal/LEY\%20GENERAL\%20DE\%20ELECTRICIDAD\%20Y\%20REGLAMENTOS.pdf

Acuerdo Gubernativo No. 2I I-2005. Reglamento de la Ley de Incentivos para el Desarrollo de Proyectos de Energía Renovable. Recuperada de http:/www.mem.gob.gt/wpcontent/uploads/2012/05/2.3-Ley-y-Reglamento-de-Incentivos-de-EnergiaRenovables.pdf

Acuerdo Gubernativo No. 21 I-2005. Reglamento de la Ley de Incentivos para el Desarrollo de Proyectos de Energía Renovable, publicado en La Gaceta, Diario Oficial del 22 de junio de 2005.

Águila Girón, M. (2005). Una Aproximación al marco jurídico que incentive el desarrollo de proyectos de energía renovable. (Tesis para optar al grado académico de licenciado en Ciencias Jurídicas y Sociales). Guatemala. Recuperada de http://biblioteca.oj.gob.gt/digitales/21676.pdf

Álvarez, W. (2016. 24. 02). Sector energético de Nicaragua urge de grandes y profundas reformas. La Prensa. Recuperado de http://www.laprensa.com.ni/2016/02/24/economia//99|265-1991265

Asociación de Generadores con Energía Renovable. (2016). Energía renovable en Guatemala. Recuperado de http://www.ager.org.gt/energia-renovable-en-guatemala/

Asociación de Renovables de Nicaragua. (20II). Plan Estratégico 201I-20/5. Recuperado de http://www.renovables.org.nimediaDocumentosPEAR-20II.pdf

Asociación de Renovables de Nicaragua. (20I2). Propuesta de Reformas al Marco legal y Regulatorio de las Fuentes Renovables de Energía en Nicaragua. Recuperado de http://www.renovables.org.ni/media/Documentos/Marco_Legal___presentacion 03-0512.pdf

Asociación Nacional de Generadores. (20I2). Sector Eléctrico Guatemalteco. Recuperado de http://www.ang.org.gt/sector-electrico-guatemaltecol

Asociación Nacional de Generadores. (2015). Mercado Eléctrico Guatemalteco: "Una Síntesis". Recuperado https://www.google.com.ni/url?sa=t\&rct=j\&q=\&esrc=s\&source=web\&cd=3\&cad=rja\&ua ct=8\&ved=0ahUKEwi327aT9aPNAhXIKiYKHdtrDEIQFggpMAI\&url=http\%3A\%2F\%2Fp royectoareca.bcie.org\%2Fget.php\%3Fdid\%3D202\&usg=AFQjCNGFEmQOL2oeBICcM Cpun4qBhe_b3w\&sig2=hYc_2x8aDttAMH7l-eEkcA\&bvm=bv. I 24272578,d.eWE

Baca, L. (2012.26.03). Geotermia, un bien desaprovechado: Nicaragua da sus primeros pasos en la explotación de este recurso. La Prensa. Recuperado de 
http://www.laprensa.com.ni/2012/03/26/economia/95436-geotermia-un-biendesaprovechado

Banco Centroamericano de Integración Económica (BCIE). (20I0). Análisis del Mercado Nicaragüense de Energía Renovable. Proyecto Acelerando las Inversiones en Energía Renovable en Centroamérica y Panamá. Recuperado el día 15 de marzo del 2016 del http://www.bcie.org/uploaded/content/category//816282752.pdf

Banco Centroamericano de Integración Económica (BCIE). (20I0). Análisis del Mercado Guatemalteco de Energía Renovable. Proyecto Acelerando las Inversiones en Energía Renovable en Centroamérica y Panamá (ARECA). Recuperado el día 25 de mayo del 2016 del http://www.bcie.org/uploaded/content/category/l07550372I.pdf

Banco Interamericano de Desarrollo (BID); Fondo Multilateral de Inversiones (FOMIN), \& Bloomberg New Energy Finance. (20I5). CLIMASCOPIO 2015. Índice de Competitividad en Energía Limpia por País. Recuperado de http://global-climatescope.org/es/

Banco Mundial. (2016.04.04). Guatemala. Panorama General. Recuperado de http://www.bancomundial.org/es/country/guatemala/overview

Carranza, M. (20I4. 26.09). ENEL sería socio en geotermia. El Nuevo Diario. Recuperado de http://www.elnuevodiario.com.ni/politica/330848-enel-seria-socio-geotermia/

Coady, D; Parry, I; Sears, L \& Shang, B. (2015). How Large Are Global Energy Subsidies? IMF. Recuperado de http://www.imf.org/external/pubs/cat/longres.aspx?sk=42940.0

Comisión Nacional de Energía Eléctrica. (2010) Ley General de Electricidad Comentada. Recuperada de https://issuu.com/jupitergua/docs/ley-general-de-electricidad-comentada

Comisión Nacional de Energía Eléctrica. (2012). Marco Legal del Sub Sector Eléctrico de Guatemala, compendio de Leyes y Reglamentos. Recuperado de http://www.cnee.gob.gt/pdf/marcolegal/LEY\%20GENERAL\%20DE\%20ELECTRICIDAD\%20Y\%20REGLAMENTOS.pdf

Consortium Legal. Centro América Abogados. (20l4). Energía Renovable en Guatemala. Recuperado de http://www.consortiumlegal.com/images/newsl/diciembre20I4/es/notas/entrevista.html

Constitución Política de la República de Guatemala. Recuperada de http://cc.gob.gt/index.php?option=com_content\&view=article\&id=219:constitucionpdf\& catid=36: catpublicaciones\&ltemid $=67$

Constitución Política de la República de Nicaragua con sus reformas incorporadas, publicada en La Gaceta, Diario Oficial No. 32 del día 18 de febrero del 2014.

Decreto 1804, Decreto de aprobación del Protocolo al Tratado Marco Del Mercado Eléctrico De América Central, publicado en La Gaceta, Diario Oficial número 15 de 23 de Enero de 1998.

Decreto A. N. Número 6497, publicado en La Gaceta, Diario Oficial número 212 del 9 de noviembre del 2011 .

Decreto A.N. No. 1778, de aprobación del Tratado Marco del Mercado Eléctrico de América Central, publicado en La Gaceta, Diario oficial número 216 del 12 de Noviembre de 1997.

Decreto Legislativo número 102, Ley Constitutiva de la Empresa Nacional de Luz y Fuerza Eléctrica, publicado en La Gaceta, Diario Oficial número 239 del 23 de Octubre de 1954.

Decreto No 52-2003. Ley de Incentivos para el Desarrollo de Proyectos de Energía Renovable, publicado en La Gaceta, Diario Oficial del 10 de noviembre de 2003.

Decreto No. 35-92, Ratificación de Protocolo de Tegucigalpa a la Carta de la Organización De Estados Centroamericanos (ODECA), Publicado en La Gaceta, Diario Oficial número 122 de 26 de Junio de 1992, recuperado el día 20 de abril del 2016 de http://www.sica.int/consulta/documento.aspx?ldn=82677\& \&ldCat=8\&ldEnt=40 I \&ldm=| \& $\underline{\text { IdmStyle }=1}$

Decreto No. 9396. Ley General de Electricidad, publicada en La Gaceta, Diario Oficial del 21 de noviembre de 1996. 
Decreto Número 52-2003. Ley de Incentivos para el Desarrollo de Proyectos de Energía Renovable. Recuperada de http://www.mem.gob.gt/wp-content/uploads/2012/05/2.3Ley-y-Reglamento-de-Incentivos-de-Energia-Renovables.pdf

Dolezal, A.; Majano, A.; Ochs, A.; Palencia, R. (2013). La ruta hacia el futuro para la Energía Renovable en Centroamérica: Evaluación de la situación actual | Mejores prácticas | Análisis de brechas. Washington, D.C.: Worldwatch Institute.

El Mundo. (2014. 15. 10). Aprueban ley que obliga incluir Estado en proyectos geotérmicos en Nicaragua. Recuperado de http://elmundo.sv/aprueban-ley-que-obliga-incluir-estado-enproyectos-geotermicos-en-nicaragual

Espinoza, C. (2016, 8 de marzo). Nicaragua es un país con grandes oportunidades económicas y energéticas. El pueblo presidente, recuperado de http://www.elpueblopresidente.com/noticias/ver/titulo:25985-nicaragua-es-un-pais-congrandes-oportunidades-economicas-y-energeticas

Estrategias y Negocios (E\&N). (20II. 20. 09). Generadora geotérmica recibe fondos para proyecto en Nicaragua. Recuperado de http://www.estrategiaynegocios.net/centroamericaymundo/centroamerica/nicaragua/47 4056-330/generadora-geotermica-recibe-fondos-para-proyecto-en-nicaragua

Fondo para el Medio Ambiente Mundial. (2009). La inversión en proyectos de Energía Renovable La experiencia del FMAM. Recuperado de https://www.thegef.org/gef/sites/thegef.org/files/publication/gefrenewenergy_ES.pdf

Gobierno de Nicaragua. (2012). Plan de Desarrollo Humano 20/2-2016. Recuperado de http://www.magfor.gob.ni/prorural/IIMesa20I2/PNDH_2012-2016_8nov2012.pdf

Gobierno de Nicaragua. (2016). Plan de Buen Gobierno 2016. Nicaragua. Recuperado de http://www.mem.gob.ni/media/file/PLAN_DE_BUEN_GOBIERNO_2016.pdf

Informe de Políticas Irena, (20I5). Energías Renovables en América Latina 20I5: Sumario de Políticas. Recuperado el día uno de marzo del 2016 de http://www.irena.org/DocumentDownloads/Publications/IRENA RE_Latin_America P olicies 2015 ES.pdf

Instituto Nacional de Estadísticas. (2015). Indicadores de densidad poblacional. Recuperado de https://www.ine.gob.gt/index.php/estadisticas/tema-indicadores

Jarquín, L. (2016. 14. 02). Nicaragua en el top tres de energías renovables. El Nuevo Diario. Recuperado de http://www.elnuevodiario.com.ni/nacionales/38497I-nicaragua-top-tresenergias-renovables/

Ley No. 695, Ley especial para el desarrollo del proyecto hidroeléctrico Tumarín, publicado en La Gaceta, Diario Oficial No. 188 del 6 de octubre del 2014.

Ley No. 620. Ley general de aguas nacionales, publicada en La Gaceta, Diario Oficial No. 169 del 04 de septiembre del 2007.

Ley número 217, Ley General del Medio Ambiente y los Recursos Naturales. Consolidada por Digesto Jurídico Nicaragüense hasta el 17 de enero del 2014, publicada en La Gaceta, Diario Oficial No. 20 del 31 de enero del 2014.

Ley número 272, Ley de la Industria Eléctrica, publicada en La Gaceta, Diario Oficial, número 172 del 10 de septiembre de 2012.

Ley número 286. Ley Especial de Exploración y Explotación de Hidrocarburos, publicada en La Gaceta, Diario Oficial número 109, del I2 Junio 1998.

Ley Número 290 Ley de Organización, Competencia y Procedimientos del Poder Ejecutivo, publicada en La Gaceta, Diario Oficial número 35 del 22 de febrero del 2013.

Ley número 443, Ley de Exploración y Explotación de Recursos Geotérmicos, consolidada según Digesto Jurídico 201I, publicada en La Gaceta, Diario Oficial No 218, del 17 de Noviembre del 2014.

Ley número 467, Ley de promoción sub-sector hidroeléctrico, publicada en La Gaceta, Diario Oficial No 174 del 12 de septiembre del año 2012.

Ley número 532, Ley para la Promoción de Generación Eléctrica con Fuentes Renovables, publicada en La Gaceta, Diario Oficial No.I75 del I 3 de septiembre del 2012. 
Ley número 554, Ley de Estabilidad Energética, consolidada por Digesto Jurídico, publicada en La Gaceta, Diario Oficial No. 175, del 13 de septiembre del 2012.

Ley número 583, Ley Creadora de la Empresa Nacional de Transmisión Eléctrica (ENATREL), publicada en La Gaceta, Diario Oficial número 04 del 05 de Enero del 2007.

Ley número 612, Ley de Reforma y Adición a la Ley No. 290, Ley de Organización, Competencia y Procedimientos del Poder Ejecutivo, publicada en La Gaceta, Diario Oficial No. 20 del 29 de Enero del 2007.

Ley número 620, Ley General de Aguas Nacionales, publicada en La Gaceta, Diario Oficial No. 169 del 04 de Septiembre del 2007.

Ley número 695, Ley Especial para el Desarrollo del Proyecto Hidroeléctrico TUMARIN, consolidado por el Digesto Jurídico Nicaragüense hasta el 13 de noviembre del 2012, publicada en La Gaceta, Diario Oficial No. 188 del 6 de octubre del 2014.

Linares, P. (2008. 22. 10). ¿Son las energías renovables de verdad más caras? Recuperado de http://www.soitu.es/soitu/2008/I0/20/medioambiente/I 224525442 722032.html

Luna Donis, P. (2014). Marco Jurídico de la Generación Distribuida Renovable en Guatemala, Chile, Costa Rica y México como otra alternativa de generación de Energía Eléctrica. (Tesis para optar al grado académico de licenciado en Ciencias Jurídicas y Sociales). Universidad Rafael Landívar. Guatemala. Recuperado del http://recursosbiblio.url.edu.gt/tesiseortiz/2014/07/0I/Luna-Pedro.pdf

Milan, J. (s.f). Curso Virtual de Cambio Climático. Recuperado de http://www.cambioclimaticoytecnologia.org/curso-gratis-cambio-climaticonicaragua/index.html

Ministerio de Energía y Minas. (2006). Energías renovables en Guatemala. Recuperado de http://www.oas.org/dsd/reeep/reuniones/uruguay/presentations/mem_guatemala.pdf

Ministerio de Energía y Minas. (2007). Energías renovables en Guatemala. Recuperado de http://repository.unm.edu/bitstream/handle//928/I2508/Energias\%20Renovables.pdf;se quence $=1$

Ministerio de Energía y Minas. (2008). Campo Geotérmico de San Jacinto-Tizate. Recuperado de http://www.mem.gob.ni/media/file/ELECTRICIDAD\%20Y\%20RECURSOS/sanjacinto\%2 0tizate\%2028\%20Agosto\%2008.pdf

Ministerio de Energía y Minas. (2009). Calendario 2009. Recuperado de http://www.mem.gob.ni/media/file/RELACIONES\%20PUBLICAS/CALENDARIOMEM.p $\underline{\mathrm{df}}$

Ministerio de Energía y Minas. (2010). Guía del Inversionista: Invirtiendo en el Sector Eléctrico de Nicaragua. Borrador. Recuperado de http://www.renovables.org.ni/media/Documentos/Guia_del_Inversionista_Sector_Elect rico de Ncaragua 2010 09Sept2010.pdf

Ministerio de Energía y Minas. (20I4). Planes Indicativos de Generación y Transmisión. Recuperado de $\quad$ http://www.mem.gob.gt/wp-content/uploads/2016/01/Planes-Indicativos-deGeneracio\%CC\%8In-y-Transmisio\%CC\%8In.pdf

Ministerio de Energía y Minas. (2016). Informe: Condición Sectorial 2015. Recuperado de http://www.mem.gob.gt/wp-content/uploads/2016/0I/CONDICl\%C3\%93NSECTORIAL-20I5.pdf

Ministerio de Energía y Minas. (2016). Nicaragua proyecta para el año 2015 Contar Con $53.99 \%$ De Participación De Energía Renovable, recuperado el día cinco de mayo del 2016 de http://www.mem.gob.ni/index.php?s=|\&idp=|74\&idt=2\&id=80|

Naciones Unidas. Comisión Económica para América Latina y el Caribe. (2014). Centroamérica: Estadísticas del Subsector Eléctrico, 2014. Recuperado el día 21 de abril de 2016 de http://repositorio.cepal.org/bitstream/handle/I |362/39226/SI50II8I_es.pdf?sequence= $\underline{1}$

Naciones Unidas. Comisión Económica para América Latina y el Caribe. (2015). Informe nacional de monitoreo de la eficiencia energética de Nicaragua, recuperado el día 20 de abril del 2016 de 
http://repositorio.cepal.org/bitstream/handle/I |362/389/0/SI500753 es.pdf?sequence= 1

Observatorio de Energías Renovables, (20II). Informe Final Nicaragua recuperado el día ocho de marzo del 2016 de http://www.renenergyobservatory.org/uploads/media/Nicaragua_Producto_I_y_2_Es p_ 02.pdf

Palacios, Luis Felipe. (2016. I4. 0I). Volcanes, la energía del futuro en Nicaragua. El Nuevo Diario, recuperado de http://www.elnuevodiario.com.ni/nacionales/382168-volcanes-energiafuturo-nicaragual

Vásquez, J. (2016. 25. 05). Entrevista Personal. Biblioteca José Coronel Urtecho (UCA).Schaffer, M. (2016.09.08). Entrevista Personal. Oficinas IC Power.

Vidaurre, A. (2013, 19 de abril). Apuesta por la hidroelectricidad. El Nuevo Diario, recuperado dehttp://www.elnuevodiario.com.ni/economia/28356I-apuesta-hidroelectricidad/ 